Geopolítica(s) Revista de estudios sobre espacio y poder ISSN: 2172-3958

https://dx.doi.org/10.5209/geop.66399

\title{
Los recursos naturales son poder: la geopolítica de las periferias latinoamericanas durante el boom de precios de materias primas y el ascenso económico de China
}

\author{
Edwin Ulises Espinoza Piguave ${ }^{1}$
}

Recibido: 10 de julio de 2017 / Aceptado: 2 de julio de 2019

Resumen. El inicio del siglo XXI se caracteriza por la crisis del orden unipolar estadounidense, cuya principal manifestación es el ascenso de las economías emergentes o semiperiferias. La disputa entre centros y semiperiferias generó el contexto para que las periferias latinoamericanas aumenten su cuota de poder global. Este artículo analiza los factores que hicieron posible el periodo de empoderamiento de la región latinoamericana a inicios del siglo XXI, la estrategia geopolítica seguida por los gobiernos de la región, los resultados de esta estrategia y el declive de su efectividad. El empoderamiento regional latinoamericano estuvo basado en una alianza de intereses geopolíticos y económicos con las semiperiferias, principalmente China; en el poder negociador que generaba la demanda mundial de sus recursos naturales; y en los ingresos recibidos por sus exportaciones. Esta estrategia era vulnerable pues su efectividad se sostenía en los recursos monetarios percibidos por la exportación primaria. Al caer los precios de los bienes primarios, los gobiernos afines al multilateralismo perdieron el apoyo de la población, así como esta nueva cuota de poder internacional. Por tanto, la estrategia latinoamericana adoleció de las mismas debilidades que su comercio exterior al estar basada en la profundización de su condición de periferia.

Palabras clave: Latinoamérica; estrategia geopolítica; boom de precios; geopolítica; centro-periferia.

\section{[en] Natural Resources are Power: The Geopolitics of Latin American Peripheries during the Boom in Raw Material Prices and the Economic Rise of China}

\begin{abstract}
The beginning of the 21st century is characterized by the crisis of the American unipolar order, whose main manifestation is the rise of emerging or semi-peripheral economies. The dispute between centers and semi-peripheries created the context for Latin American peripheries to increase their share of global power. This article analyzes the factors that made possible the period of empowerment of the Latin American region at the beginning of the 21st century, the geopolitical strategy followed by the governments of the region, the results of this strategy and the decline in its effectiveness. The Latin American regional empowerment was based on an alliance of geopolitical and economic interests with the semi-peripheries, mainly China; in the negotiating power that generated the world demand for its natural resources; and in the income received from its exports. This strategy was vulnerable because its effectiveness was sustained by the monetary resources perceived by primary
\end{abstract}

1 Facultad de Ciencias Económicas, Universidad de Guayaquil (Ecuador).

E-mail: edwin.espinozap@ug.edu.ec 
exports. As prices of primary goods fell, governments related to multilateralism lost the support of the population, as well as this new share of international power. Therefore, the Latin American strategy suffered from the same weaknesses as its foreign trade, being based on the deepening of its periphery status.

Keywords: Latin America; geopolitical strategy; price boom; geopolitics; center-periphery.

\section{[pt] Recursos naturais são poder: a geopolítica das periferias latino- americanas durante o boom dos preços das matérias-primas e a ascensão econômica da China}

Resumo. O início do século XXI é caracterizado pela crise da ordem unipolar americana, cuja principal manifestação é o surgimento de economias emergentes ou semi-periféricas. A disputa entre centros e semiperiferia criou o contexto para as periferias latino-americanas aumentarem sua participação no poder global. Este artigo analisa os fatores que possibilitaram o período de empoderamento da região da América Latina no início do século XXI, a estratégia geopolítica seguida pelos governos da região, os resultados dessa estratégia e o declínio de sua eficácia. O empoderamento regional da América Latina foi baseado em uma aliança de interesses geopolíticos e econômicos com as semiperiferia, principalmente a China; no poder de negociação que gerou a demanda mundial por seus recursos naturais; e na receita recebida de suas exportações. Essa estratégia era vulnerável porque sua eficácia era sustentada pelos recursos monetários percebidos pelas exportações primárias. À medida que os preços dos bens primários caíam, os governos relacionados ao multilateralismo perderam o apoio da população, bem como essa nova parcela do poder internacional. Portanto, a estratégia latino-americana sofria das mesmas fragilidades do comércio exterior, baseando-se no aprofundamento de sua condição de periferia.

Palavras-chave: América Latina; estratégia geopolítica; aumento de preços; geopolítica; centro-periferia.

Sumario. Introducción. La redistribución mundial del poder en las primeras dos décadas del siglo XXI. 1. Campos petroleros, reservas de energía y de poder: la nueva dinámica de las compañías petroleras emergentes. 2. El nacionalismo de los commodities en el boom de precios de las materias primas. 2.1. Latinoamérica desafía a los centros anglosajones a través de sus recursos naturales. 2.2. El nuevo ciclo político latinoamericano. 2.3. Latinoamérica y China: recursos naturales a cambio de poder. 3. Precios volátiles, poder geopolítico frágil: el declive del nuevo ciclo político latinoamericano. 3.1. El trágico fin del multilateralismo latinoamericano. 4. Sin embargo, las reservas de recursos son poder. La dependencia vista al revés. Conclusiones. Bibliografía.

Cómo citar: Espinoza Piguave, Edwin Ulises (2019) “Los recursos naturales son poder: la geopolítica de las periferias latinoamericanas durante el boom de precios de materias primas y el ascenso económico de China". Geopolítica(s). Revista de estudios sobre espacio y poder, vol. 10, núm. 2, 229-258.

\section{Introducción. La redistribución mundial del poder en las primeras dos décadas del siglo XXI}

El orden jerárquico de los poderes globales, que rige el destino de mundo desde fines de la Segunda Guerra Mundial, ha entrado en una fase de crisis desde los inicios del siglo XXI. La hegemonía unipolar estadounidense ha caído en un proceso de marcada decadencia. Existen nuevas tendencias hacia la multilateralidad, cuya manifestación más clara es el enfrentamiento de los bloques de poder centrales del Norte, contra los bloques emergentes (Merino, 2016). 
Las potencias regionales como las que integran el llamado BRICS (Brasil, Rusia, India, China y Sudáfrica) tuvieron un papel económico y geopolítico destacado a nivel global desde los años 1990, y desde la década de los 2000 se evidenció que su creciente poderío las estaba llevando hacia la cúspide de la pirámide jerárquica de las naciones, generándose así una nueva distribución global de poderes (Morales Ruvalcaba, Rocha \& Vargas, 2014). Esta nueva distribución del poder mundial se manifiesta en la tendencia a la consolidación de gigantescos bloques geográficos y económicos, en la forma de Estados continentales como Rusia, Brasil y China (Narodowski \& Merino, 2015). Por tanto, ya no existen visos del poder unipolar global que se suponía ejercería Estados Unidos al desintegrarse la Unión Soviética.

La idea del declive estadounidense y el orden multipolar que le sucediera, ha sido explorada por diversos autores de visiones distintas e incluso antagónicas. Brzezinski (2009) pronosticaba un mundo hexapolar dirigido por Estados Unidos, la Unión Europea, Rusia, China, India y Japón. El historiador y analista político, Timothy Garton Ash (2007) narraba que desde fines del siglo XX se evidenciaba que la unipolaridad estadounidense ya no era viable. El poder global se había esparcido hacia nuevos Estados-naciones que antagonizaban con los centros tradicionales, y hacia nuevos actores civiles que reemplazaban al poder de los Estados. Había una nueva tendencia a la multipolaridad del poder.

Jalife (2007) comentaba que el mundo estaba derivando hacia una "desglobalización con regionalización", refiriéndose con este término geopolítico a que la globalización unipolar, neoliberal, estadounidense estaba llegando a su fin y sería reemplazada por un nuevo orden de potencias regionales con economías fuertemente intervenidas por los Estados, que extenderían su hegemonía sobre grandes áreas geográficas del planeta. Así, el mundo postglobalización estaría dirigido por Rusia, China y el propio Estados Unidos, cada uno gobernando su región geográfica inmediata y compartiendo la hegemonía global. Es decir, no solo se producirían cambios de paradigmas económicos, como el tránsito brusco del liberalismo a la intervención estatal; sino, además, este nuevo proceso conllevaría redistribuciones geográficas tanto del poder como del producto global.

Por su parte, Wallerstein (2005), vislumbraba también un detrimento del poder hegemónico de EE UU en el futuro, pero tenía un pronóstico más pesimista que los autores anteriores. Wallerstein hablaba del advenimiento de un "caos", donde el despotismo y el abuso aumentarían conforme el poder de los Estados se fuera deteriorando. Al respecto decía: "Esto agudizará, sin duda, la medida de violencia cotidiana en el sistema-mundo. Será ineludiblemente espantoso para la mayoría de la gente" (Wallerstein, 2005: 16).

En todo caso, es una opinión generalizada entre los estudiosos de la geopolítica global que el declive de la supremacía estadounidense desembocaría en un mundo caracterizado por la presencia de grandes regiones, dirigidas por Estados-nación fuertes militar e industrialmente, y que las economías emergentes tendrían un lugar de primer nivel ese nuevo orden. No en vano, ya en el presente, "los BRICS son los líderes del conjunto de las potencias regionales y de los Estados semiperiféricos" (Morales Ruvalcaba, Rocha \& Vargas, 2014: 254); por lo tanto, se perfilan como las economías que en un corto o mediano plazo dirigirían el mundo multipolar.

Sin embargo, es muy difícil realizar pronósticos precisos sobre la futura configuración del espacio-poder y del espacio-economía del planeta. El deterioro de la hegemonía occidental se presenta como el factor constante, pero no existen certezas 
sobre qué unidades económico-territoriales son las que ejercerán las nuevas hegemonías. En este sentido, tanto la distribución de la producción como del poder se han redireccionado hacia las economías emergentes, pero, últimamente, este redireccionamiento tiende a concentrarse geográficamente en Asia ${ }^{2}$. Así, el termino BRICS, comenzó reduciéndose a BRIC, luego de excluir a Sudáfrica como líder regional futuro, y últimamente podría incluso reducirse a RIC, considerando los problemas socioeconómicos y sociopolíticos a los que se enfrenta Brasil.

Si algo caracteriza a esta etapa de decadencia de la hegemonía estadounidense, es su turbulencia e inestabilidad geopolítica. Los tiempos predecibles de la Guerra Fría fueron "un paraíso en comparación con el presente" (Sputnik, 2007). No obstante, esta época de inestabilidades lo ha sido también de oportunidades para el empoderamiento de regiones no industrializadas. La competencia entre bloques emergentes y centros occidentales hizo que regiones de menor peso económico y militar eleven también su cuota de poder. Así, Latinoamérica, o más concretamente Sudamérica, tuvo una actuación relevante en ese periodo de disputa y redistribución del poder de inicios del siglo XXI. Por eso, el crecimiento de la producción y del poder de las potencias emergentes, fue un factor fundamental del empoderamiento latinoamericano a partir del comienzo del siglo XXI.

Por otra parte, existe un agudizamiento de la competencia entre centros y economías emergentes o semiperiferias por el acceso a los recursos naturales de las regiones periféricas. El bloque de periferias latinoamericanas es un importante oferente de esas codiciadas e imprescindibles materias primas; y a inicios del siglo XXI, fue la región que más profundizó su comercio con las semiperiferias como China (CEPAL, 2012a). Ese ambiente de competencia por recursos naturales entre regiones industriales generó un periodo de empoderamiento para América Latina. La región emergió, aunque en menor medida que las semiperiferias, como bloque que intentó integrarse y elevar su cuota global de poder (Merino, 2016). Así, Latinoamérica, en buena medida, se "desconectaba" del ciclo sistémico de acumulación principal y se "conectaba" al nuevo ciclo de acumulación asiático ${ }^{3}$. Este breve periodo de "desconexión" (Amin, 2001) sería producto de la competencia por sus recursos naturales.

Sin embargo, este nuevo y breve periodo de empoderamiento global para el bloque Latinoamericano, tuvo también una relación muy estrecha con el nuevo superciclo de precios de las materias primas que se observó desde los inicios del siglo XXI (Erten \& Ocampo, 2013). Los precios reales de las materias primas llegaron a máximos históricos, como se observa en el Gráfico 1. El precio real del petróleo en 2012 fue 18,28 veces el precio real de 1970. El precio real del gas natural en US\$ llegó en 2005 a 13,88 veces el de 1970. El precio real del oro llegó en 2012 a casi 10 veces el de 1970. En los demás productos primarios (alimenticios, minerales no

2 En 2017, China es la economía con mayor PIB PPA (medido con el método de paridad del poder adquisitivo), con \$23.301 miles de millones. China ha superado a Estados Unidos e incluso a la Unión Europea en su conjunto. India tiene en 2017 un PIB PPA de \$ 9.454 miles de millones, y ya hace varios años ha sobrepasado a Japón y a Alemania. Brasil e Indonesia han superado a Reino Unido (Banco Mundial, 2019b). Esto revela un fuerte avance de las economías emergentes en las jerarquías de la producción global, pero sobre todo las asiáticas.

3 Arrighi (2007) definía al "ciclo sistémico de acumulación”, como aquel periodo temporal en que una potencia hegemónica era el centro de las actividades económicas mundiales y su mayor beneficiaria. Así, se reconocía la existencia de cuatro ciclos sistémicos históricos de acumulación: el ciclo genovés, el holandés, el británico y el estadounidense. Al parecer, la decadencia de la hegemonía estadounidense está abriendo paso a un incipiente ciclo que parecía tendrá como centro hegemónico a China. 
combustibles, etc.) se observan también importantes alzas desde de los inicios del siglo XXI; pero las mayores, por mucho, estuvieron en los productos energéticos como el petróleo. No obstante, se observa también que los precios tuvieron una baja generalizada desde aproximadamente 2013 .

Gráfico 1. Índice de precios internacionales de productos primarios (Precios reales en dólares de 2010 divididos para el precio real de 1970)

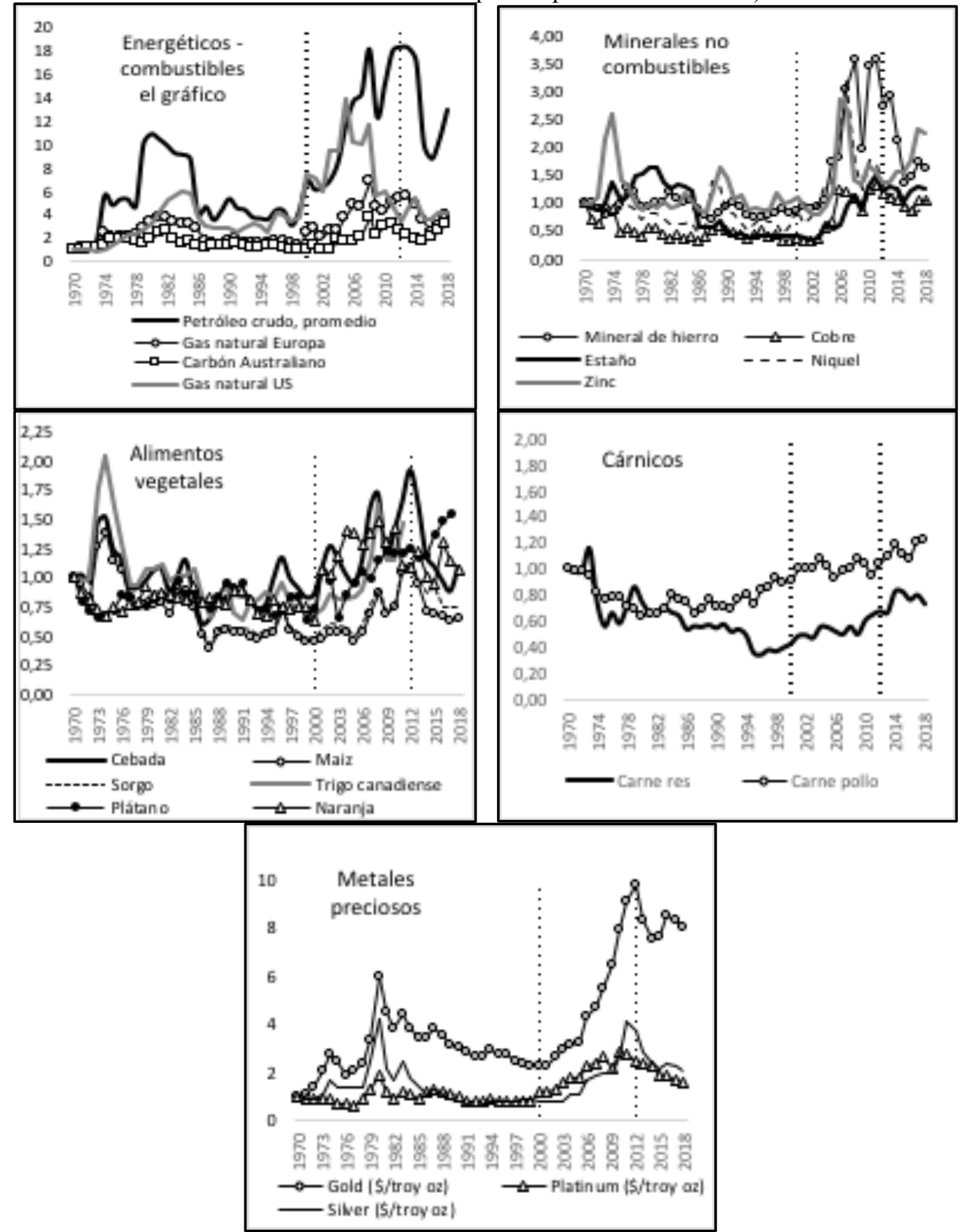

Fuente: Banco Mundial, abril de 2019. Elaboración propia. 
Esta nueva etapa de acumulación de reservas permitió a los países latinoamericanos emprender proyectos de desarrollo interno, inversión en educación, construcción de infraestructuras, etc., que consolidaron el apoyo popular a los movimientos políticos en los gobiernos. Además, los ingresos recibidos por los precios al alza de sus exportaciones les permitieron garantizar y acceder a préstamos de las instituciones de crédito chinas. Esta inédita situación disminuyó la dependencia hacia las instituciones financieras occidentales, como el FMI, cuyas exigencias generalmente violentaban la autonomía de las economías latinoamericanas.

China contaba con grandes excedentes financieros, empresas constructoras en expansión y una demanda creciente de materias primas; mientras, las economías latinoamericanas tenían grandes reservas de materias primas y necesitaban financiamiento y construcción de infraestructuras. Ambas regiones buscaban, además, ascender en la escala de poder geopolítico global. Esta consonancia de intereses hizo que naciera una nueva sociedad entre periferias y centros emergentes. Las necesidades materiales, cada vez mayores, del crecimiento económico de China, la acercaban a Latinoamérica. En 2010, China consumió 40\% del total de consumo mundial de cobre (CEPAL, 2012b); esto lo convirtió en el socio comercial más importante de Chile y Perú. En 2012, China consumió 67,6\% del total mundial de consumo de soja (USDA, 2012); esto lo convirtió en un gran socio comercial de Argentina. Así, rápidamente se convirtió en el mayor demandante de las exportaciones de varios países de la región y el mayor oferente de crédito, debilitando la posición hegemónica de EE UU.

Entonces, con las arcas llenas por los precios al alza y el respaldo financiero de China, los gobiernos latinoamericanos, sobre todo los sudamericanos, emprendieron la construcción de instituciones regionales de diálogo y gobernanza que elevaron su poder de negociación frente a los centros, sacándolos del área de influencia estadounidense y acercándolos a la de las economías emergentes. Así se inició un ciclo de cambios políticos regionales, con el encumbramiento de gobiernos latinoamericanos afines a las tendencias a la multilateralidad que venían siendo encabezadas por las economías emergentes.

Por tanto, la demanda de las economías emergentes, sobre todo China, que agudizó la competencia internacional por las materias primas y llevó al alza sus precios, produjo también un ciclo de empoderamiento para las periferias latinoamericanas frente a los centros tradicionales de Occidente.

No obstante, este empoderamiento, por estar basado en los volátiles precios de las materias primas, básicamente de índole extractiva y energética, tuvo un marcado declive a partir de 2014, cuando aquellos precios volvieron a tender a la baja. Esto hizo también que la tendencia al alza de la acumulación de reservas se ralentiza o se revierte en la mayoría de los países latinoamericanos analizados (ver Gráfico 2).

Aunque los estrategas geopolíticos latinoamericanos tuvieron aciertos que elevaron el poder de la región, no existió el complemento de políticas estatales de industrialización, que, bajo un enfoque estructural, pudiesen haber disminuido la vulnerabilidad ante los vaivenes de los precios de las materias primas.

Utilizando los términos de Frank (1976), la región entró en un periodo de "involución capitalista "al debilitarse sus lazos con los centros, pero esta involución no 
fue activa ${ }^{4}$. A fin de cuentas, la estrategia latinoamericana estuvo apuntalada en el poder que generaban los ingresos por la elevación de sus exportaciones primarias. Por tanto, no resultó en la superación, sino en una profundización de su condición geopolíticamente periférica.

Gráfico 2. Total de reservas (incluye oro, miles de millones de US\$ a precios actuales)

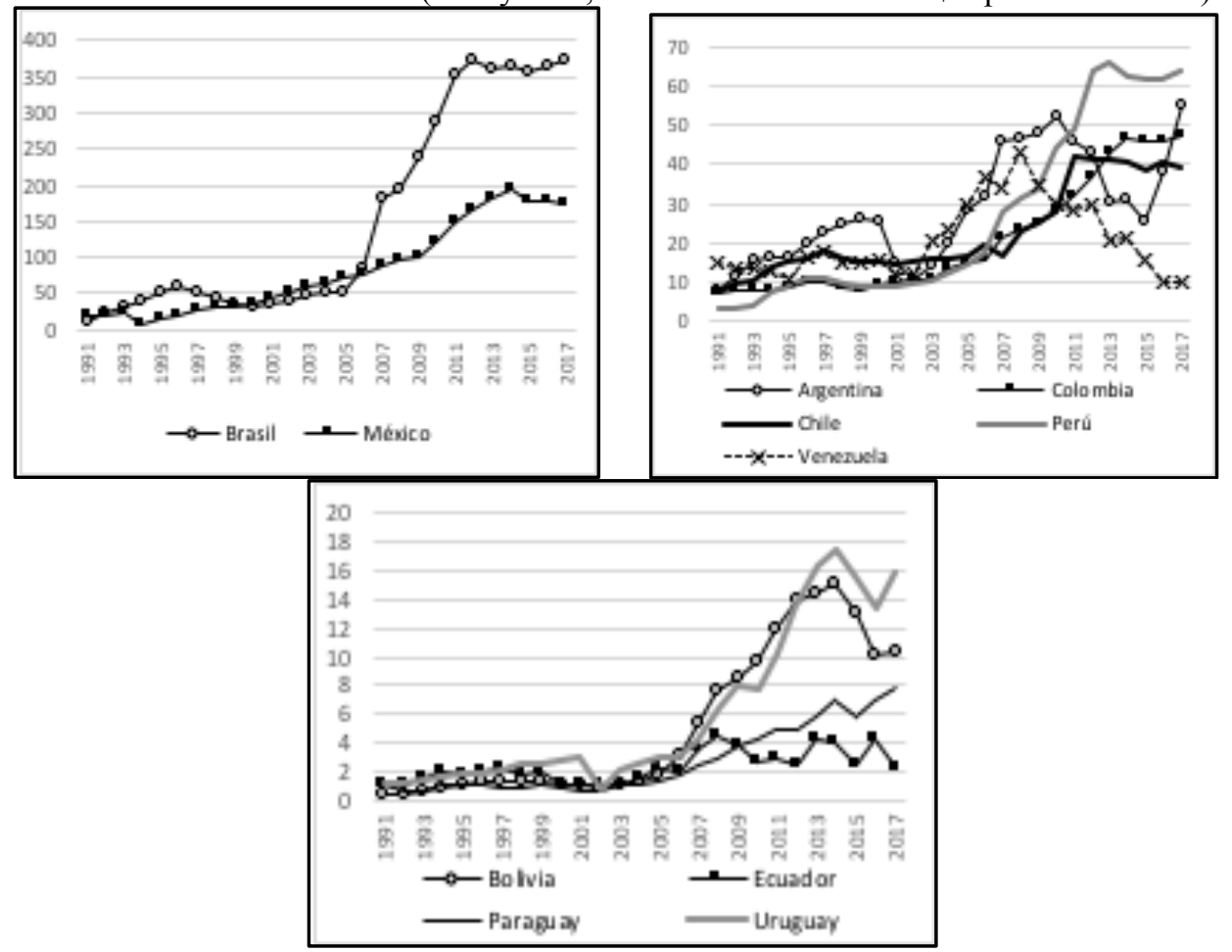

Fuente: Banco Mundial, abril de 2019. Elaboración propia.

Entonces, se puede afirmar que hubo un periodo de empoderamiento de la región latinoamericana a nivel global en los primeros lustros del siglo XXI. Este periodo de avance de la región en la jerarquía geopolítica y geoestratégica de poder mundial estuvo estrechamente relacionado con dos fenómenos: el boom de precios y exportaciones de las materias primas; y el acercamiento de las economías emergentes como China, que en su afán de elevar su posición de poder buscaron en Latinoamérica un oportuno y ventajoso aliado, fundamentalmente comercial.

Por la importancia para Latinoamérica del periodo histórico descrito, en este artículo se estudian las particularidades, los progresos y los retrocesos más destacables, de la estrategia latinoamericana de empoderamiento durante este, geopolíticamente turbulento, inicio del siglo XXI.

$4 \quad$ Frank (1976) planteaba que cuando la hegemonía de los centros entra en crisis, las periferias entran bien en "involución capitalista activa", es decir, en un periodo de industrialización, o en "involución capitalista pasiva", es decir, en un periodo de precariedad y subsistencia. Si bien estos conceptos de Frank no ajustan a la perfección con los hallazgos de este trabajo, son útiles para las recomendaciones finales. 


\section{Campos petroleros, reservas de energía y de poder: la nueva dinámica de las compañías petroleras emergentes}

Los nuevos precios de los productos primarios elevaron la cuota de poder global de Latinoamérica y demás periferias. Pero el petróleo, que fue el que tuvo la mayor alza de precios, fue también el que generó la mayor elevación del poder. Por tanto, esta sección se dedica al estudio de esa cuota de poder generada por el alza del precio del petróleo.

Hace ya varias décadas, Enrico Mattei, presidente de la ENI (Ente Nazionale Idrocarburi) italiana, acunó el término "Las Siete Hermanas" refiriéndose de manera sarcástica a las grandes petroleras occidentales que entonces dominaban el mercado mundial, y que se habían cartelizado para obtener ventajas monopólicas, atropellando todo principio de libre comercio.

A continuación, se señala cuáles eran estas siete compañías petrolíferas y sus países de procedencia (Tabla 1$)$.

Tabla 1. Las "Siete Hermanas"

\begin{tabular}{|c|l|l|}
\hline \multicolumn{1}{|c|}{ Compañia } & \multicolumn{1}{|c|}{ País de procedencia } \\
\hline 1 & Standard Oil & Estados Unidos \\
\hline 2 & Royal Dutch Shell & Países Bajos, Reino Unido \\
\hline 3 & $\begin{array}{l}\text { Anglo-Iranian Oil Company (AIOC), que luego se } \\
\text { llamaría British Petroleum (BP) }\end{array}$ & Reino Unido \\
\hline 4 & Standard Oil of New York, que pasó a ser Mobil & Estados Unidos \\
\hline 5 & $\begin{array}{l}\text { Standard Oil of California, que pasó a llamarse } \\
\text { Chevron }\end{array}$ & Estados Unidos \\
\hline 6 & Gulf Oil Corporation & Estados Unidos \\
\hline 7 & Texaco & Estados Unidos \\
\hline
\end{tabular}

Fuente: (Hoyos, 2007). Elaboración propia.

Estas empresas dominaban casi absolutamente los procesos de extracción, procesamiento y distribución de petróleo en el mundo. Desde los albores del siglo XX compitieron por el liderazgo mundial del sector, pero a partir del fin de la Segunda Guerra Mundial, coordinaron acuerdos que les proporcionaron ganancias propias de un cartel monopólico. Es importante hacer observar que todas las "Siete Hermanas" eran originarias de países occidentales: cinco estadounidenses, una británica, y una británico-holandesa. Esto reflejaba el enorme poderío anglosajón sobre el más determinante y estratégico de los recursos energéticos en el mundo, cuyo control otorga un fuerte poder geopolítico. Posteriormente, las "Siete Hermanas" terminaron en fusiones que redujeron su número, pero no su poder de control sobre el mercado del petróleo. Chevron, Royal Dutch Shell, Exxon Mobil y British Petroleum, fueron el resultado de estas fusiones. Pero, si bien la estructura de este cartel cambió durante el siglo XX, su procedencia occidental y mayoritariamente anglosajona siguió siendo su principal característica. El cartel de las "Siete Hermanas" tenía un formidable poder de negociación geopolítica sobre los países productores de petróleo. Esta 
“omnipotencia" duró hasta mediados de los 1970 en que la OPEP puso en cuestionamiento la capacidad del cartel de imponer su voluntad a los productores.

Luego, a partir de 2002, con la subida del precio internacional del petróleo, comienza un nuevo periodo de empoderamiento de las compañías petroleras de los países productores, que puso en apuros a la hegemonía anglosajona. Estas empresas fueron calificadas por el Financial Times como las "Siete Nuevas Hermanas" (Tabla 2).

Tabla 2. Las nuevas "Siete Hermanas"

\begin{tabular}{|c|l|l|}
\hline & \multicolumn{1}{|c|}{ Compañia } & \multicolumn{1}{c|}{ País de procedencia } \\
\hline 1 & Saudi Aramco & Arabia Saudita \\
\hline 2 & Gazprom & Rusia \\
\hline 3 & CNPC, China National Petroleum Corporation & China \\
\hline 4 & NIOC, National Iranian Oil Company & Irán \\
\hline 5 & PDVSA & Venezuela \\
\hline 6 & Petrobras & Brasil \\
\hline 7 & Petronas & Malasia \\
\hline
\end{tabular}

Fuente: (Hoyos, 2007). Elaboración propia.

Estas empresas, en su mayoría de propiedad estatal, controlaban en 2007 cerca de un tercio de la producción mundial de petróleo y gas, y poseían un tercio de las reservas totales de estos recursos (Hoyos, 2007).

En contraste, las anteriores "Siete Hermanas" (ahora cuatro), controlaban en 2007 solo $10 \%$ de la producción mundial y $3 \%$ de las reservas de petróleo y gas. Sin embargo, sus ingresos siguieron siendo más altos que los de las hermanas nuevas, pues las viejas "Siete Hermanas" producen y comercian no solo petróleo y gas sino también derivados como gasolina, diésel y productos de la industria petroquímica (Hoyos, 2007).

El renovado empoderamiento geopolítico de las nuevas "Siete Hermanas" petroleras estatales (con la excepción de CNPC) estaba basado en la posesión territorial de las reservas del recurso; así como en la competencia internacional de los centros por el acceso a éste, que se había acrecentado debido a la demanda de las economías emergentes como China. Robin West, presidente de PFC Energy, se atrevía a decir que ahora las nuevas "Siete Hermanas" eran las ponedoras de reglas en los mercados internacionales (Hoyos, 2007). Esas afirmaciones no parecían exageradas cuando se leían los reportes de las agencias encargadas de estudiar el mercado. La Agencia Internacional de la Energía, organismo de vigilancia sectorial de los países desarrollados, calculaba que en los siguientes 40 años el 90\% de los nuevos suministros vendrían de los países en desarrollo. La mayor parte del consumo futuro de petróleo de los países desarrollados vendría de Saudi Aramco. Esto convertiría a Arabia Saudita en el "banquero central de la producción petrolífera" y marcaría una clara diferencia en un mundo hasta poco antes abastecido por las compañías petroleras occidentales (Hoyos, 2007). 
De todas maneras, Arabia Saudita es actualmente una economía bastante alineada a la hegemonía occidental. No obstante, el empoderamiento saudita les resulta incómodo, aunque la mayor fuente de preocupación de Occidente proviene del empoderamiento de compañías más pequeñas como Gazprom de Rusia y PetroChina de China. Estas dos empresas desplazaron a British Petroleum y Shell del liderazgo mundial en las bolsas de valores (valor de sus acciones) en 2006 (Hoyos, 2007).

Entonces, con esta nueva sensación de autoridad de las semiperiferias y periferias, derivada de la posesión de un recurso tan estratégico como el petróleo —así como de otras materias primas como los minerales no combustibles-, en un momento de elevada demanda, comienza la era del "nacionalismo petrolero". Esta nueva época de nacionalismos periféricos ha puesto en apuros la histórica hegemonía de las petroleras anglosajonas y, en consecuencia, el poder geopolítico de los centros occidentales.

\section{El nacionalismo de las commodities en el boom de precios de las materias pri- mas}

\subsection{Latinoamérica desafía a los centros anglosajones a través de sus recursos naturales}

La mayor vulnerabilidad de la globalización anglosajona ${ }^{5}$ está en su dependencia de productos energéticos como el petróleo (Jalife, 2007). Es decir, el poder estas economías, así como el estilo de vida de sus habitantes, se basa en un elevado consumo de materia y energía. Buena parte de esa carga energética proviene de recursos como petróleo o gas natural. Sin embargo, la oferta y reservas mundiales de estos bienes extractivos se encuentran mayoritariamente en las periferias y semiperiferias, muchas de ellas no afines a la política exterior angloestadounidense. Por tanto, el control geopolítico sobre estas regiones poseedoras de grandes reservas era vital para el sostenimiento del liderazgo anglosajón. Este dominio se vio amenazado cuando las economías petroleras comenzaron un nuevo ciclo de tendencias nacionalistas.

Al comenzar el siglo XXI, el petróleo volvió a ser objeto de un intenso nacionalismo de parte de los gobiernos de los países productores (Jalife, 2007). Latinoamérica afirmó su autoridad sobre sus recursos naturales y Rusia usó la dependencia de Occidente de su petróleo y gas para incrementar su influencia geopolítica. Esto, junto a la no consolidación de la invasión estadounidense a Irak, representó un complejo y preocupante panorama energético para estadounidenses y británicos. Uno a uno, los gobiernos de los países petroleros, como los latinoamericanos, utilizaron sus reservas del subsuelo para aumentar su poder negociador frente a los centros occidentales. Por supuesto, esto generó puntos de tensión. Por ejemplo, las advertencias de Hugo Chávez de cortar el suministro petrolero a EE UU, se convirtieron en una preocupación para el Comando Sur estadounidense, pues eran una seria amenaza para su seguridad energética (Jalife, 2007).

Jalife (2007) usa el término "globalización anglosajona" para referirse a los procesos globalizadores basados en la apertura comercial, dirigidos por las economías anglosajonas, Estados Unidos y Gran Bretaña. Según Jalife, aquel periodo y forma de globalización está llegando a su fin y es reemplazado por un nuevo ciclo de reempoderamiento de las potencias regionales como las BRICS. 
En realidad, el nacionalismo petrolero surgido en Latinoamérica a inicios del siglo XXI era eficaz porque se apoyaba en otros hechos como la no consolidación del proyecto para un nuevo siglo americano en Medio Oriente (Arrighi, 2007), el ascenso económico de las economías emergentes como China y el nuevo ciclo alcista de precios de las materias primas.

En este marco coyuntural bastante propicio para sus intereses geopolíticos, las economías petroleras emprendieron un ciclo de nacionalizaciones de sus reservas y control estatal sobre las exportaciones de estos productos extractivos. En varios países se cambiaron las modalidades de contratos con las compañías extractoras internacionales, volviéndolos más favorables a los Estados locales. De esta manera hubo una recuperación de la renta en un momento de grandes excedentes por la subida mundial de precios. Los Estados de las economías latinoamericanas con reservas de hidrocarburos eran los que tenían mayores posibilidades de recuperación de la renta en el boom de precios, pues contaban con los instrumentos fiscales para hacerlo. Esto no pasaba con los Estados del resto de economías latinoamericanas exportadoras de minerales no combustibles y productos agrícolas, cuyos ingresos se elevaron, pero no lo hicieron de forma tan intensa como en las economías petroleras-gaseras (CEPAL, 2013). Por eso, el nacionalismo de recursos naturales fue más "agresivo" en las economías petroleras. Pero todo el nacionalismo de recursos naturales era percibido como una amenaza para la seguridad energética de EE UU, pues revelaba que éste no tenía ya el mismo control de antes sobre los productores.

Según un reporte del Comando Sur estadounidense, "la extensión del control estatal sobre la producción de energía en varios países disuade las inversiones esenciales para incrementar y sostener el abasto petrolero en el largo plazo" (citado en Jalife, 2007: 43). Esta afirmación de corte neoliberal y neocolonialista aludía al mercado, pero claramente era parte de la estrategia geopolítica estadounidense para menoscabar la posible intención de las periferias de usar sus recursos para empoderarse. El hecho de que sea el Comando Sur la institución que realice esta afirmación, técnica en las apariencias, era una muestra de que la seguridad energética estadounidense es un asunto de índole estratégico-militar, no sólo comercial. No obstante, en el nuevo ciclo político latinoamericano, recomendaciones neoliberales de este tipo no tenían ya cabida.

Hay que entender que la globalización neoliberal era un discurso pregonado desde el mundo anglosajón que recomendaba la apertura a ultranza al resto de economías. En esa argumentación teórica, conceptos como la soberanía, la estrategia geopolítica, la protección a los sectores estratégicos, etc., eran calificados como arcaicos, propios de las ideas atrasadas de la "izquierda caduca".

Sin embargo, el más claro ejemplo de proteccionismo, y de la búsqueda de todo lo mencionado con anterioridad lo dio EE UU cuando los capitales chinos de la China National Overseas Oil Company (CNOOC) quisieron adquirir la empresa petrolera californiana UNOCAL. Estas intenciones de compra fueron combatidas por las autoridades estatales estadounidenses, acusando a China de querer apoderarse de la economía local. Finalmente, ChevronTexaco llegó a un acuerdo de compra de UNOCAL por \$18.000 millones (El País, 2005). En este caso hubo una evidente y deliberada política de protección de un sector estratégico para EE UU, así como un claro ejemplo del avance de los capitales chinos en Occidente. Por tanto, las recomendaciones neoliberales que ven al mercado como medio y fin, no son seguidas por sus pregoneros anglosajones. Además, esta acción de EE UU deja una enseñanza 
contraria a su discurso: que la estrategia geopolítica no debe dejarse de lado a la hora del cálculo económico.

Así pensaron los estrategas latinoamericanos durante el boom de precios, y con base a ello utilizaron sus recursos naturales como herramienta geopolítica. El primer gobierno latinoamericano en usarlos, y que tuvo más roces con la política exterior estadounidense, fue el de Venezuela. Como un intento de ganar poder frente al centro hegemónico, el ministro de Energía venezolano, Rafael Ramírez, dijo en Irán, durante una visita oficial de Chávez en 2006, que si EE UU mostraba una política hostil hacia Venezuela, dejaría de exportar petróleo a ese país. En consecuencia, Richard Lugar, presidente del Comité de Relaciones Exteriores del Senado estadounidense, pidió al gobierno de Bush desarrollar un plan de contingencia en caso de que esto pudiera llegar a ocurrir. El US Government Accountability Office estimó que si se diera el corte de suministros petroleros venezolanos el precio se incrementaría en 11 dólares aproximadamente (Webb-Vidal, 2006a). Sin embargo, Bernardo Álvares, Embajador venezolano en EE UU, aclaró que eso solo ocurriría en circunstancias extraordinarias, como, por ejemplo, en caso de agresión al gobierno de Chávez, y que Venezuela deseaba seguir ofreciendo petróleo para Estados Unidos. Por su parte, Roger Tissot, director para Latinoamérica de PFC Energy, consultora estadounidense, dijo que Venezuela no soportaría dejar de exportar petróleo a su país en el corto y mediano plazo; pero puntualizó también que, si EE UU hiciera algo que amenazara al gobierno de Chávez, era probable que este efectivamente usara el petróleo como arma (Webb-Vidal, 2006a).

Es decir, tanto la tenencia de recursos estratégicos, como la dependencia de los centros hacia estos, son factores de empoderamiento para las periferias. Sin embargo, la dependencia de las periferias de los recursos financieros y de la demanda de los centros, no permite aun una verdadera igualación de poderes. Latinoamérica no puede, solo con sus recursos naturales, presentar un verdadero desafío a la hegemonía occidental. Necesita para esto la colaboración y alianza de las economías emergentes y potencias militares no occidentales. Y de hecho la buscó; por ejemplo, en 2006, Chávez visitó Rusia con una agenda que incluía la compra de 30 jets rusos Sukhoi Su-30, 30 helicópteros militares, 100.000 rifles de asalto Kalashnikov, y una posible licencia para fabricar Kalashnikov en Venezuela (Webb-Vidal, 2006b). Tom Casey, portavoz del Departamento de Estado de EE UU, expresó a Rusia su preocupación por la venta de aviones de combate a Venezuela y pidió a los rusos reconsiderar la transacción. La visita de Chávez a Rusia fue seguida por visitas a otros países con relaciones tensas con EE UU. Ivan Safranchuk, del think-tank World Security Institute, dijo que el recibimiento de Chávez en Rusia revelaba las intenciones rusas de construir - e incluso liderar - un bloque de países antiestadounidenses (WebbVidal, 2006b).

Es decir, la búsqueda de poder frente al centro estadounidense, sustentada en la estrategia geopolítica de nacionalizar y proteger sus cuantiosos recursos naturales, resultó en un acercamiento de las periferias latinoamericanas con las economías emergentes y potencias militares como Rusia. Estas aproximaciones, resultantes del nuevo nacionalismo petrolero, convulsionaron la distribución del poder hegemónico instaurada en el planeta tras la finalización de la Segunda Guerra Mundial y, más concretamente, desde la caída del Muro de Berlín.

En este nuevo contexto geopolítico planetario, Venezuela aprobó en 2007 una ley para obtener el control mayoritario de los yacimientos del cinturón del Orinoco. El 
Estado ruso por su parte arrebató a Shell un proyecto de extracción de gas natural por \$ 20.000 millones (Hoyos, 2007).

El impacto del nuevo nacionalismo petrolero fue mayor que el de los 1970 debido a una importante cuestión: en 1975, ante el brote de nacionalismo de entonces, Gulf retiró sus capitales del mundo en vías de desarrollo y se dedicó a invertir mayoritariamente en Norteamérica y el mar del Norte. Es decir, las empresas anglosajonas tenían aun yacimientos que explorar con los cuales reemplazar aquellos que los productores del Sur le negaban. Pero en 2007, las compañías petroleras tenían cada vez más difícil el acceso a yacimientos nuevos. Según informaba el Financial Times, no se había descubierto ningún yacimiento capaz de bombear más de 1 millón de barriles diarios desde hace varias décadas atrás (Hoyos, 2007).

Por otro lado, las economías petroleras periféricas como Ecuador, Venezuela, Irán, etc., dedicaron una importante proporción de los ingresos obtenidos durante el boom de precios a la construcción de infraestructuras, entrega de subsidios e inversión social en general. También, en algunos casos, se usaron estos recursos para incrementar el poderío militar. Esto generó preocupaciones en el mundo desarrollado pues las ganancias no estaban siendo utilizadas por los países abastecedores para explorar nuevos yacimientos como se esperaba desde los centros. Así, las periferias petroleras intentaban proteger sus recursos naturales no dilapidándolos, sino aprovechando su escasez relativa para aminorar el retraso de sus sociedades respecto a los centros. El presidente venezolano Hugo Chávez, según informaba el Financial Times, gastaba dos tercios del presupuesto de PDVSA en sus "programas sociales populistas", en vez de reinvertir en la extracción de petróleo (Hoyos, 2007). Asimismo, Rusia no estaba invirtiendo en la mejoría de su obsoleto sistema de gasoductos; Irán no explotaba sus reservas de gas natural de South Pars, ni reinvertía lo suficiente para aumentar su extracción de petróleo, sino que mantenía un elevado nivel de subsidios internos con sus ganancias petroleras (Hoyos, 2007).

A este nuevo nacionalismo, que preocupaba a los centros, se sumaba la nueva e históricamente insólita competencia por recursos con las economías emergentes. Jimmy Carter, expresidente de EE UU, que enfrentó la crisis de abastecimiento petrolero de los 1970s, explicaba que la inseguridad energética era cada vez mayor. La situación era más preocupante que entonces pues ahora EE UU debía enfrentar la competencia de China e India (Hoyos, 2007).

Además, las petroleras de las economías emergentes empezaban a operar autónomamente en la extracción y comercio de recursos, restando espacio a las transnacionales de los centros. China, a través de la CNPC, había extendido sus inversiones en exploración a través del planeta, en búsqueda de su seguridad energética y para impulsar su enorme crecimiento. Petrobras estaba explorando por si misma las aguas costeras brasileñas y con esas habilidades adquiridas, exploraba también el Golfo de México y la costa de Angola, compitiendo con Exxon Mobil y British Petroleum. Petronas de Malasia también competía con las compañías occidentales en Sudán y Birmania (Hoyos, 2007).

En este orden de ideas, Hoyos (2007), en el artículo del Financial Times que se ha usado en esta argumentación, considera que este importante cambio en la estructura de poder de las transnacionales petroleras se debió a la resurrección del "nacionalismo de los recursos naturales". Como puede apreciarse, esta reedición del nacionalismo de las periferias fue posible gracias a dos factores fundamentales: la 
coincidencia de su estrategia geopolítica con las semiperiferias, y los ingresos alcanzados por la subida global de precios, sobre todo del petróleo.

Esto revela diversos puntos de fortaleza y a la vez de vulnerabilidad de las periferias petroleras. El empoderamiento estuvo basado en la posesión del recurso, sin embargo, este solo fue posible debido a la subida coyuntural de precios de esta riqueza natural del subsuelo. Es decir, el factor de poder fue el volátil precio de las materias primas. Por tanto, esta forma de empoderamiento adoleció de la recurrente vulnerabilidad en la estructura comercial de las periferias, pues dependía de las fluctuaciones de precios, que, si bien se rigen por la oferta de los exportadores, también están dictadas por la demanda de los países industrializados.

Adicionalmente, como indica Hoyos (2007), las "Siete Hermanas" mayores, si bien han sido superadas en tamaño por las nuevas "Siete Hermanas", aún conservan la importantísima ventaja de exportar no solo petróleo y gas natural, sino derivados, manteniendo así el liderazgo mundial en la industria petroquímica. Las petroleras periféricas, no igualaron, ni se acercaron, a ese liderazgo industrial de las petroleras centrales. Esto muestra que las vulnerabilidades de las periferias se mantuvieron incluso en este periodo de empoderamiento. Estas debilidades más gravosas son, tanto las fluctuaciones de precios de sus exportaciones, como el atraso tecnológico relativo que genera el exportar productos de escaso valor agregado.

Sin embargo, Jalife (2007) argumentaba que la "globalización geo energética" es más profunda aun que lo expresado por Hoyos (2007). Para Jalife, la pérdida de poder de las transnacionales petroleras occidentales surgió de la derrota militar anglosajona en Irak. En la primavera de 2004 quedó en evidencia que la invasión no había logrado su objetivo de controlar los pozos petroleros de la segunda reserva más grande de la OPEP. Jalife menciona, como consecuencia de lo anterior, dos elementos de lo que denominaba la "nueva ecuación del siglo XXI": "desplome del dólar y auge de los dos binomios, petróleo/gas y oro/plata" (Jalife, 2007: 47), y añade:

La derrota geoestratégica de EE UU en Irak le quita la cobertura nuclear a la globalización financiera anglosajona, lo que se profundiza con la devaluación del dólar y su debilitamiento como moneda de reserva unipolar, y la probable recesión de la economía de Washington, panorama que se complica con sus déficits consuetudinarios, sus múltiples burbujas especulativas y su deuda impagable (Jalife, 2007: 50).

\subsection{EI nuevo ciclo político latinoamericano}

Entonces, la primera década del siglo XXI se caracterizó por una conjunción inédita de fenómenos interrelacionados que debilitó la hegemonía estadounidense: 1) EE UU y los centros occidentales enfrentaron fuertes crisis económicas y disminuyeron su participación global en la demanda de materias primas; 2) la demanda china reemplazó esa caída de la demanda occidental; 3) los precios de las materias primas tuvieron una muy importante alza; 4) el dólar tuvo un periodo de preocupante devaluación hasta 2014, y 5) Estados Unidos había sufrido una profunda derrota económica y moral por el fracaso de la invasión a Irak y su proyecto geopolítico en Medio Oriente había fracasado.

En este contexto de debilidad estadounidense, fue posible para las periferias latinoamericanas, aplicar una política internacional de confrontación con los centros 
anglosajones, que décadas atrás hubiese sido simplemente impensable. Estas confrontaciones comenzaron con las victorias electorales de movimientos cuestionadores a la hegemonía anglosajona. Desde inicios de la década de los 2000, Latinoamérica vivió un nuevo ciclo político regional. En 1999, Hugo Chávez inicia su presidencia en Venezuela, convirtiéndose en el primero de una serie de presidentes latinoamericanos que marcaron distancia con la política exterior estadounidense y británica. Chávez impulsaría la reactivación de la Organización de Países Exportadores de Petróleo, OPEP, y utilizaría los dólares obtenidos con las exportaciones petroleras para promover la integración regional. La principal iniciativa de Chávez fue el ALBA (Alianza Bolivariana para los Pueblos de Nuestra América) que fue una clara contestación al ALCA (Área de Libre Comercio de las Américas) promovida por EE UU.

A su vez, Chávez encontró respaldo regional en el ciclo de victorias electorales de movimientos afines en mayor o menor grado a sus propuestas en casi toda Latinoamérica, pero principalmente en Sudamérica. En 2003, Ignacio "Lula" da Silva gana la presidencia de Brasil. Lula emprendió relaciones con Irán y Corea del Norte y pidió reformas al FMI en un claro desafío a la geopolítica estadounidense (Aljazeera, 2010). Néstor Kirchner, también en 2003, asumiría la presidencia en Argentina. Su medida insigne, fue el pago anticipado de la deuda externa con el FMI (Clarín, 2005), para así poner alto a las imposiciones políticas de ese organismo internacional. En 2006 gana la presidencia de Bolivia, Evo Morales del Movimiento al Socialismo (MAS). Morales estatizó las minas de estaño de Huanuni y el complejo metalero de Vinto. Estas dos fuentes de recursos estaban hasta entonces en manos de la compañía anglo-suiza-holandesa GLENCORE, la más grande empresa de comercialización de materias primas del planeta. Morales obligó a las empresas extractoras de petróleo a entregar su producción a la empresa pública boliviana YPFB para que esta la comercialice. Así, el Estado se quedaría con el $82 \%$ de los ingresos por explotación de petróleo. Algo semejante ocurrió en Ecuador, donde el presidente electo en 2006, Rafael Correa, anunció que revisaría los contratos petroleros para revertir la cuota de ganancia del Estado y las transnacionales extractoras (El Universo, 2007). Con el nuevo trato, el reparto de los ingresos sería de $80 \%$ para el Estado y $20 \%$ para las extractoras; antes, esta relación era la contraria. Además, en 2007, el gobierno ecuatoriano anunció que había cancelado su deuda con el FMI (Ecuador Inmediato, 2007), y que no volvería a contratar prestamos con ese organismo ni a firmar cartas de intención (Observatorio de la Política Fiscal, 2007). De esta forma, Ecuador, así como Venezuela y Argentina, marcaba distancias con el FMI, dando muestras de soberanía política y administrativa.

Estos desafíos a la hegemonía estadounidense no se dieron solo en el plano económico, sino también político, tocando incluso lo militar. En 2009, el Gobierno ecuatoriano decide no renovar el contrato de la base militar de EE UU en Manta (El Universo, 2009). Este fue un evidente cambio de rumbo, desde la obsecuencia a la política exterior estadounidense, a un firme intento de afirmación de la soberanía estatal ecuatoriana.

Pero los ejemplos más emblemáticos de desafío de las periferias latinoamericanas a los centros anglosajones, fueron el caso "Julian Assange", y la respuesta regional a las maniobras militares inglesas en las Malvinas en 2010. Assange, periodista fundador del portal Wikileaks, había filtrado videos y documentos diplomáticos que involucraban al ejército estadounidense en violaciones a los derechos humanos en Irak. 
Aduciendo ser perseguido por el gobierno de EE UU, pidió asilo diplomático en la embajada de Ecuador en Londres. El amparo fue concedido y las autoridades británicas amenazaron con entrar y arrestarlo, violando la soberanía de la embajada ecuatoriana. El ALBA, reunida en Guayaquil en agosto de 2012, respaldó a Ecuador en su decisión de conceder el asilo, y expresó su rechazo a las amenazas británicas de violentar la embajada ecuatoriana. Asimismo, UNASUR ${ }^{6}$ reunió también sus cancilleres en Guayaquil, condenó la amenaza británica y respaldó a Ecuador en su decisión (Deutsche Welle, 2012).

En 2010 se desató una nueva crisis diplomática entre Argentina y Gran Bretaña por las Islas Malvinas, pues el gobierno argentino protestó cuando las empresas británicas iniciaron exploraciones para buscar petróleo en los mares de las islas. Gran Bretaña respondió con intimidantes maniobras militares marítimas. El MERCOSUR $^{7}$ decide entonces no recibir barcos con bandera británica de las Malvinas en los puertos de sus miembros (Últimas Noticias, 2011). En el bloque del ALBA, el presidente ecuatoriano, fue incluso más atrevido al proponer sanciones económicas contra Gran Bretaña (El Nuevo Herald, 2012). Latinoamérica, con sus organismos regionales respondía así, como bloque, a las amenazas de los centros anglosajones.

Estos roces con la hegemonía anglosajona evidenciaban la recuperación de soberanía en las decisiones políticas exteriores en Latinoamérica. Pero estas muestras de autoridad estatal y regional iban fuertemente atadas a la recuperación de la renta que se hizo posible debido al alza de precios de las materias primas, así como al respaldo de las economías emergentes. Por ejemplo, Argentina recibió el respaldo de China y Rusia en sus aspiraciones de recuperar las Malvinas. Esto generó preocupadas declaraciones en el mundo anglosajón que antes habrían sido impensables, pues Londres expresó su temor a que Argentina recupere las islas con ayuda de China ( $\mathrm{La}$ Nación, 2011).

Estas inéditas manifestaciones de soberanía fueron factibles porque durante el periodo del boom de precios los gobiernos latinoamericanos habían construido organismos regionales de dialogo como el ALBA y el UNASUR, en los cuales no participaba EE UU. Estas asociaciones corporativas de la periferia en Latinoamérica eran intentos de desembarazarse de las presiones políticas estadounidenses en la OEA y ganar poder frente a los centros occidentales, que, en los casos anteriormente mencionados, resultaron efectivos.

Incluso, se crearon medios regionales de comunicación de masas como la cadena TELESUR, que en sus inicios era financiada por los Estados venezolano, cubano, ecuatoriano, nicaragüense y argentino. TELESUR competía con las tradicionales cadenas informativas como BBC y $\mathrm{CNN}$, que dominaban de manera casi absoluta la información internacional que llegaba a los televidentes latinoamericanos y que respondía a intereses ingleses y estadounidenses.

6 UNASUR está constituida por: Argentina, Bolivia, Brasil, Colombia, Chile, Ecuador, Guyana, Paraguay, Perú, Surinam, Uruguay, y Venezuela.

7 MERCOSUR es un tratado comercial regional, de aranceles comunes y libre circulación de mercancías, sus miembros son Argentina, Brasil, Paraguay, Uruguay y Venezuela; mientras Bolivia, Chile, Colombia, Ecuador y Perú son miembros asociados. 


\subsection{Latinoamérica y China: recursos naturales a cambio de poder}

La estrategia geopolítica de empoderamiento de los países latinoamericanos, encontró complementariedades con dos dimensiones de la estrategia geopolítica china. Primero, el principio chino de no intervención, y segundo, la búsqueda de China de un sistema multipolar (Rodríguez \& Leiva Van de Maele, 2013).

A las periferias les sobraban reservas de recursos naturales, a las economías emergentes les sobraban reservas de divisas internacionales. Esto generó una simbiosis, que fue aprovechada por ambos grupos de países. Del acercamiento económico, surgió un acercamiento geopolítico en el cual los centros quedaron de lado. Por tanto, la estrategia geopolítica latinoamericana de los primeros años del siglo XXI estuvo fuertemente entrelazada con los intereses económicos y aspiraciones geopolíticas de las economías emergentes, sobre todo China.

Autores como Rocha \& Morales Ruvalcaba (2011), sostenían que las "potencias regionales", como China, India o Brasil, tenían un comportamiento geopolítico distinto a las "potencias medias" como Suiza o Noruega. Las potencias medias, en general, son colaboradoras del sistema internacional que sostiene la hegemonía de las potencias mundiales como EE UU; mientras que las potencias regionales son en general cuestionadoras y modificadoras de ese sistema. Sin embargo, el alcance del poder de las potencias regionales es menor que el de las medias y bastante menor que el de las mundiales, pues este poder zonal se circunscribe a su región geográfica.

Pero la excepción era precisamente China, la única potencia regional cuyo poder tiene alcance global. Por tanto, era la economía emergente o potencia regional más adecuada para las alianzas geopolíticas que aspiraba la región latinoamericana. Por eso, cuando los bloques regionales latinoamericanos buscaron acercamientos a las economías emergentes, fue China la que respondió a esta llamada geopolítica con mayor interés. Se establecieron diálogos entre el gobierno chino y MERCOSUR, CEPAL, OEA, UNASUR. China empezó conversaciones con los bloques regionales latinoamericanos interesados tanto en la expansión de sus negocios como en la disminución de las presiones de los organismos de crédito y de gobernanza occidentales. El 16 de julio de 2014 en Brasilia, se realizó la primera reunión entre el BRICS y UNASUR. Un día después BRICS lanzaba su fondo de reserva y banco de desarrollo; fondos financieros que se ponían a disposición de las periferias. Mediante estos acercamientos China buscó un trato regional, y ya no solo bilateral con los países de Latinoamérica. Estas aproximaciones elevaron la posición de poder de la región latinoamericana en el mundo.

Sin embargo, cabe señalar que los acercamientos se dieron bajo la posición de desigualdad y subordinación geopolítica que supone para Latinoamérica el tutelaje del poderío económico-financiero de la potencia asiática. La oferta de créditos chinos fue uno de los motores principales de estos "acuerdos".

Por otra parte, China por su cuenta, mediante su poder financiero, había ya ampliado su influencia en los organismos regionales americanos. China fue aceptado como observador permanente de la OEA en 2004 (OEA, 2004) y como miembro del Banco interamericano de desarrollo en 2009 (BID, 2009). Es decir, China llevaba la iniciativa y su posición negociadora era más fuerte que la latinoamericana.

Pero la cooperación no quedó solo en el área económica. Se dieron maniobras militares entre China y Perú, así como intercambios de visitas de oficiales militares latinoamericanos y chinos. China participó en la misión de estabilización de las 
Naciones Unidas en Haití (Rodríguez \& Leiva van de Maele, 2013). China también realizó un préstamo de $\$ 300$ millones a Bolivia, que se acompañaba de un trato para suministrar vehículos y cooperación técnica para el ejército boliviano (Gulévich, 2013). Es decir, la asistencia militar china en Latinoamérica formó también parte del acercamiento a la región.

Igualmente, hubo transferencias de tecnología aeroespacial y cooperación en tecnología nuclear china a países latinoamericanos, como en el caso de Argentina. Varias naciones latinoamericanas usaron instalaciones chinas para lanzar sus satélites al espacio. Ecuador lanzó su primer satélite espacial desde el cosmódromo Jiuquan de China en abril de 2013.

China ofrecía así, con sus recursos financieros, un aval de globalidad a las aspiraciones regionales latinoamericanas mientras obtenía además un espacio para colocar sus excedentes de capital y abastecerse de recursos naturales.

Por tanto, también desde esta perspectiva, el empoderamiento de Latinoamérica estuvo basado en dos hechos circunstanciales de corta duración e interrelacionados: el boom de precios de las materias primas que le generó ingresos extraordinarios, y la demanda de las economías emergentes que le suscitó vínculos geopolíticos con éstas. Como comentaba Marisela Svampa "En el último decenio, América Latina realizó el pasaje del Consenso de Washington, asentado sobre la valorización financiera, al «Consenso de los Commodities», basado en la exportación de bienes primarios en gran escala" (Svampa, 2013: 30). Se había entrado de este modo en un nuevo ciclo político, pero basado en el mismo modelo de inserción, ahora con las economías emergentes como China como principales socios. La dominación de los centros occidentales retrocedía, pero continuaban, e incluso se acentuaban las viejas vulnerabilidades. Latinoamérica entraba al nuevo mundo multipolar, ofreciendo lo mismo que le ofrecía al feneciente mundo unipolar estadounidense, recursos naturales a cambio de recursos financieros. El papel histórico de periferia de la región continuaba.

\section{Precios volátiles, poder geopolítico frágil: el declive del nuevo ciclo político latinoamericano}

Latinoamérica había creado organismos regionales de diálogo sin influencia estadounidense; $\mathrm{y}$, a través de ellos, había respondido en conjunto a las amenazas de los centros anglosajones. Además, la región se había liberado de la condicionante dependencia a los organismos financieros occidentales. Definitivamente era un nuevo ciclo político y la estrategia geopolítica había sido correcta. Pero este periodo histórico se soportaba en la frágil elevación de los precios de los commodities y terminaría si éstos volvían a su tradicional tendencia a la baja.

El elevado gasto público que había reconstruido la infraestructura vial, educativa y sanitaria en la región, y que mantenía la popularidad de los gobiernos afines al multilateralismo, no tendría continuidad si disminuían los ingresos por exportaciones. Por tanto, se debía construir una estrategia de inserción al mundo más consistente, para reducir esa endémica vulnerabilidad, que tarde o tempano habría de volver. Resultaba indispensable destinar los excedentes de renta a proyectos de cambio de matriz productiva. En algunos casos, como en Ecuador, estos proyectos fueron 
iniciados, pero también fueron muy pronto alcanzados por la nueva crisis de precios de las materias primas.

Poseer grandes reservas de recursos naturales fue una virtud que permitió a las periferias latinoamericanas ejercer su soberanía en el marco del nuevo periodo de nacionalismo de recursos naturales, pero fue también su mayor fragilidad cuando el boom de precios terminó.

Desde 2014, ocurrieron fenómenos que revitalizaron la debilitada hegemonía anglosajona, pues el dólar se revalorizó y el precio del petróleo cayó estrepitosamente. El poder negociador de las periferias y semiperiferias disminuyó de forma considerable. Pero las periferias latinoamericanas, sobre todo las petroleras como Venezuela y Ecuador, fueron las más perturbadas por la nueva situación geopolítica que afectó grandemente su recién inaugurada posición de poder. En cambio, esto no fue así para las semiperiferias como Rusia o China, cuyo poderío industrial-militar, así como el alcance de sus influencias regionales, siguieron dejándoles una cuota de poder suficiente para seguir desafiando la hegemonía occidental. Es decir, la fortaleza que otorgaron a Latinoamérica los vaivenes del precio del petróleo y las materias primas, se la quitaron nuevamente estos mismos altibajos del precio del petróleo, en particular, y las materias primas en general.

Pero, la principal y más profunda causa de las vulnerabilidades latinoamericanas, más allá de las fuertes y constantes fluctuaciones transnacionales de los precios de sus recursos naturales, sigue siendo su retraso tecnológico frente a los centros. Esto quedó demostrado cuando en noviembre de 2016, la OPEP decidió nuevamente anunciar un recorte de la producción petrolera en dos millones de barriles diarios, con la intención de que los precios vuelvan a subir. Efectivamente, se observó una tibia alza de 43,77 dólares por barril en noviembre a 51,78 en diciembre de 2016 (Banco Mundial, 2019a), pero esta vez la maniobra no tuvo la efectividad de los años 1970.

Ya desde hace algunos años, las economías industrializadas habían comenzado a desarrollar tecnologías que les permitían extraer petróleo de profundidades cada vez mayores en los lechos marinos. Asimismo, se había desarrollado, hasta volverse rentable, la técnica de extracción de petróleo y gas conocida como fracking o "fractura hidráulica", que, si bien origina incalculables costos socio-ecológicos, permite tener acceso al petróleo atrapado entre las rocas que con los métodos convencionales nunca seria alcanzable. De esta forma, EE UU pasó a tener 264.000 millones de barriles en reservas de petróleo; esto es, una cantidad mayor que las provisiones de Arabia Saudita (CNN, 2016a).

Por su parte, ante esta amenaza que convertía en inefectiva la estrategia de la OPEP, Arabia Saudita decide abandonar el plan original y elevar su producción, ahora, con la paradójica intención de que el precio del petróleo caiga aún más. El plan saudita era propiciar que el precio del petróleo caiga tanto que vuelva no rentable la extracción por fracking, la cual es considerablemente más cara que la convencional. Así los sauditas evitarían que se disminuya la dependencia geopolítica de los centros hacia su petróleo. Sin embargo, la maniobra saudita solo era lucrativa para su economía, que tenía unas reservas de petróleo muy fáciles de extraer y, por tanto, unos costos muy bajos. Mientras, las economías latinoamericanas, con costos de extracción mucho mayores, vieron caer, junto a los precios del petróleo, sus aspiraciones de volver al periodo de empoderamiento. 
Por tanto, la vulnerabilidad de las periferias, si bien se manifiesta fundamentalmente en la recurrente caída de los precios internacionales de sus bienes naturales, tiene como fuente primigenia su atraso tecnológico frente a los centros.

\subsection{El trágico fin del multilateralismo latinoamericano}

Los gobiernos latinoamericanos de tendencias nacionalistas, con distintos tipos de discursos, algunos de izquierda tradicional, otros con planteamientos ideológicos autóctonos, algunos más antioccidentales que otros, comenzaron a retroceder al final del boom de precios. Los movimientos políticos tradicionales o de "derecha" — si se prefiere el termino-, más afines a la política exterior estadounidense, recuperaron espacios electorales, y generaron la percepción de un posible fin del ciclo político latinoamericano de "izquierda" — si es que también se prefiere el término-.

Los gobiernos regionales con tendencias al multilateralismo - quizá el termino más adecuado para este estudio - perdieron aceleradamente su popularidad, en medio de acusaciones de corrupción, grandes déficits fiscales y caídas de las tasas de empleo en casi toda la región. Así, Venezuela entró en un periodo de inflación que anula todo avance en el bienestar de sus ciudadanos, Argentina vuelve a tener problemas de depreciación de su tipo de cambio, el crecimiento de Ecuador cae junto al precio del petróleo. En medio de esta problemática y el ascenso de gobiernos afines a la derecha política y económica, la región vuelve la mirada a la política exterior estadounidense.

Brasil, el más crucial de los países latinoamericanos, es el primer golpeado y el centro de lo que aparentemente sería una operación de EE UU para recuperar su hegemonía regional. En 2014 comienza la operación Lava Jato que empezó investigando casos de lavado de dinero y luego involucró a Petrobras y a las grandes constructoras brasileñas cuyas operaciones se habían expandido regionalmente $(\mathrm{CNN}$, 2016b). Esta maniobra trastornó el nuevo orden político sudamericano, implicando a casi todos los gobiernos en actos de corrupción con empresas brasileñas. El caso más conocido fue el de la constructora Odebrecht, que involucra a ex gobernantes de Panamá, Colombia, Ecuador, Perú, etc. (BBC, 2018). Odebrecht es una constructora con la interesante peculiaridad de que también participaba en el área de defensa y en el mayor proyecto de las fuerzas armadas brasileñas: la construcción del primer submarino nuclear brasileño. Odebrecht trabajaba junto a la empresa francesa DCNS en un programa de transferencia que aportaba mucho a la independencia tecnológica de Brasil. Por eso, las fuerzas armadas brasileñas manifestaron sus sospechas de un plan dirigido por EE UU para boicotear sus recientes intenciones de construir submarinos nucleares y ganar poder como potencia regional (Machado \& Zibechi, 2016).

Así mismo, algunos pensadores, como Luis Moniz (2016), argumentaban que Brasil está embarcado en una batalla geopolítica en la que EE UU le ha asestado un duro golpe para debilitarlo y recuperar su poder sobre la región. En 2016, el Senado Federal destituyó a la presidente de Brasil, Dilma Rousseff, sucesora de Lula Da Silva. El cargo fue asumido por Michel Temer, quien anunció ajustes en los sistemas de pensiones, desregulaciones laborales, contracción del gasto público y elevación del protagonismo de los empresarios en sectores claves del gobierno. Además, Temer anunciaba que cambiaría el rumbo de la política exterior brasileña (Caetano, 2019). Esto afectaba fuertemente los intentos de integración del bloque 
sudamericano que, aunque atendían sobre todo los intereses de Brasil (Van Klaveren, 2018), contribuían al fortalecimiento de todos los países integrantes.

La nueva posición geopolítica brasileña cambió las prioridades y temas de discusión en el MERCOSUR. En 2017, este bloque regional decide suspender a Venezuela alegando que había roto el orden democrático (MERCOSUR, 2017). Una vez sin Venezuela, MERCOSUR abandonaba el paradigma integracionista y volvía al "comercialista-liberal" (Caetano, 2019).

Con el presidente de Argentina, de clara orientación de derecha, Mauricio Macri, presidiendo MERCOSUR, se hicieron más fuertes las voces que pedían integrarse con la Alianza del Pacifico, bloque más afín a la política exterior estadounidense. En marzo de 2019, Lenin Moreno, nuevo presidente de Ecuador, anunció que saldría oficialmente de UNASUR. Antes, ya había anunciado que pediría la reversión de la propiedad del edificio sede, que funcionaba en la capital ecuatoriana (El Telégrafo, 2018). Esto fue un duro golpe a la estructura administrativa de UNASUR, que ya venía mostrando fragilidad. Es decir, los dos bloques regionales más importantes de Sudamérica dieron un giro dramático, MERCOSUR hacia Occidente, UNASUR hacia su posible muerte.

Con este declive del ciclo de gobiernos multilateralitas, comienza un retorno regional a la influencia del FMI. Argentina y Ecuador vuelven a los diálogos con este organismo para que les abra líneas de crédito y para ello comienzan a aplicar políticas de reducción de subsidios a la gasolina, gas de uso doméstico, presupuestos para educación, etc. (Clarín, 2018; FMI, 2019). Ambos casos de retorno al fondomonetarismo son representativos, pues tanto los gobiernos de Ecuador como Argentina, durante la década anterior, habían anunciado que cancelaban su deuda con el FMI para librarse de sus exigencias e intromisiones.

Ecuador terminó con el asilo de Julian Assange entregándolo a la policía británica (Hispan TV, 2019); además, anunció que en 2020 será sede de las maniobras "Unitas", con la marina de guerra estadounidense (Sputnik, 2019). Así, el país que fue sede del parlamento de UNASUR, vuelve la mirada al norte, hacia el decadente, pero aun pujante, centro hegemónico estadounidense.

\section{Sin embargo, las reservas de recursos son poder. La dependencia vista al re- vés}

La crisis de hegemonía de Occidente, el periodo de cambio de centro hegemónico, en que las economías emergentes compiten con los centros por los recursos naturales, creó el espacio que las periferias necesitaban para exigir su cuota de poder. Lastimosamente este poder fue tan efímero y vulnerable como lo fue el boom de precios de las materias primas. Pero la persistencia de esas vulnerabilidades, anteriormente descritas, no significa que no sea útil usar la posesión de recursos naturales como herramienta geopolítica. La lección que deja el fin del boom es que la estrategia aplicada debió incluir un plan para disminuir esas vulnerabilidades estructurales. Es decir, la geopolítica latinoamericana del boom de precios debió acompañarse de una estrategia regional de industrialización endógena de sus recursos naturales.

Latinoamérica no puede desprenderse del determinismo al que la condiciona su dotación de factores, abundante en recursos naturales. En ese sentido, tanto la demanda de los centros como la de las economías emergentes seguirán enviándole 
estímulos para la continuación de su condición de periferia. Entonces, la única forma de convertir estos recursos naturales en ventaja y no en condena es usando el poder de oferta que generan para negociar e incluso exigir tratados de transferencia tecnológica y así emprender un proceso de industrialización y avance técnico-científico.

A pesar de sus avatares históricos, Latinoamérica sigue siendo la región más importante, la más estratégica como abastecedora de recursos energéticos y materiales para el desarrollo del sistema capitalista mundial. Latinoamérica y el Caribe tienen las mayores reservas de petróleo no descubiertas del planeta (USGS, 2012) y las segundas mayores ya probadas, superadas solo por Medio Oriente (OLADE, 2012). UNASUR, hasta ahora el bloque latinoamericano que ha alcanzado mayor poder geopolítico y extensión territorial (ver Gráfico 3), concentra en su suelo más de $90 \%$ de las reservas mundiales de niobio, $59,68 \%$ de las de litio - otras fuentes estiman aún más-, $53,80 \%$ de las de renio, $31,77 \%$ de las de cobre, $26,79 \%$ de las de plata, $25,93 \%$ de las de grafito, $25,10 \%$ de las de estaño, $24,12 \%$ de las de Molibdeno, $18,33 \%$ de las de tierras raras, $17,70 \%$ de las de níquel, $14 \%$ de las de zinc, $8,70 \%$ de las de oro, etc. (USGS, 2018). Todos estos son minerales de capital importancia en la nueva etapa del capitalismo global, dominada por la electrónica; pero son más importante geopolíticamente, ya que varios son productos de elevada vulnerabilidad para EE UU, pues depende fuertemente de sus importaciones (Bruckmann, 2012).

UNASUR también tiene el 10\% de las tierras cultivables del planeta (Banco Mundial, 2019b). El bloque produce el 12,34\% del maíz producido mundialmente, el $11,76 \%$ del cacao, $15,38 \%$ del plátano, $6,70 \%$ de los cereales, tiene el $21,15 \%$ de las cabezas de ganado del planeta, y el 10,38\% de las aves de corral (Actualitix, 2018) ${ }^{8}$ (ver Gráfico 3). Esto muestra el fuerte poder negociador que tendría UNASUR si llegara a consolidarse como bloque geopolíticamente poderoso a nivel global. Si, además, UNASUR u otro bloque, llegase a incorporar a México y el Caribe, regiones similares y afines en intereses geopolíticos, estructuras económicas, vulnerabilidades, e incluso, cultura, se tendría un poder negociador determinante en la jerarquía global del poder.

A manera de ejemplo de la capacidad negociadora que brindan las reservas de recursos naturales, tenemos lo que hizo China al poseer grandes reservas de tierras preciosas, material usado en la fabricación de televisores y monitores de alta tecnología. Los dos gigantes de la fabricación de pantallas, LG Displays y Samsumg Electronics Co., transfirieron sus plantas a China debido a la presión ejercida por ésta al concentrar en su territorio los mayores depósitos de este material, y además un creciente mercado interno para dichos productos (Bruckmann, 2012). Esto ilustra el poder de negociación que puede lograrse con una política que aproveche la posesión de recursos naturales, usándola como herramienta de presión contra los centros hegemónicos.

A fin de cuentas, así como Latinoamérica depende de la tecnología y fuentes financieras de los centros, los centros dependen de los recursos naturales de las periferias para continuar su crecimiento. Como manifestaba Falconí (2013), este periodo es diferente al pasado, pues nunca los centros habían dependido tanto de las periferias. El boom de precios se esfumó, pero la dependencia de los centros a las materias

Los datos de la producción de maíz, ganado, aves de corral y cereales corresponden a 2014. Los datos de la producción de grano de cacao y plátano corresponden a 2013 (Actualitix, 2018). 
primas latinoamericanas seguirá presente y las fuerzas políticas interesadas en el empoderamiento regional seguirán latentes, esperando su nueva oportunidad.

Gráfico 3. Reservas de recursos mineros, tierras cultivables y producción de recursos agrícolas de países de UNASUR (porcentajes del total mundial) ${ }^{1}$

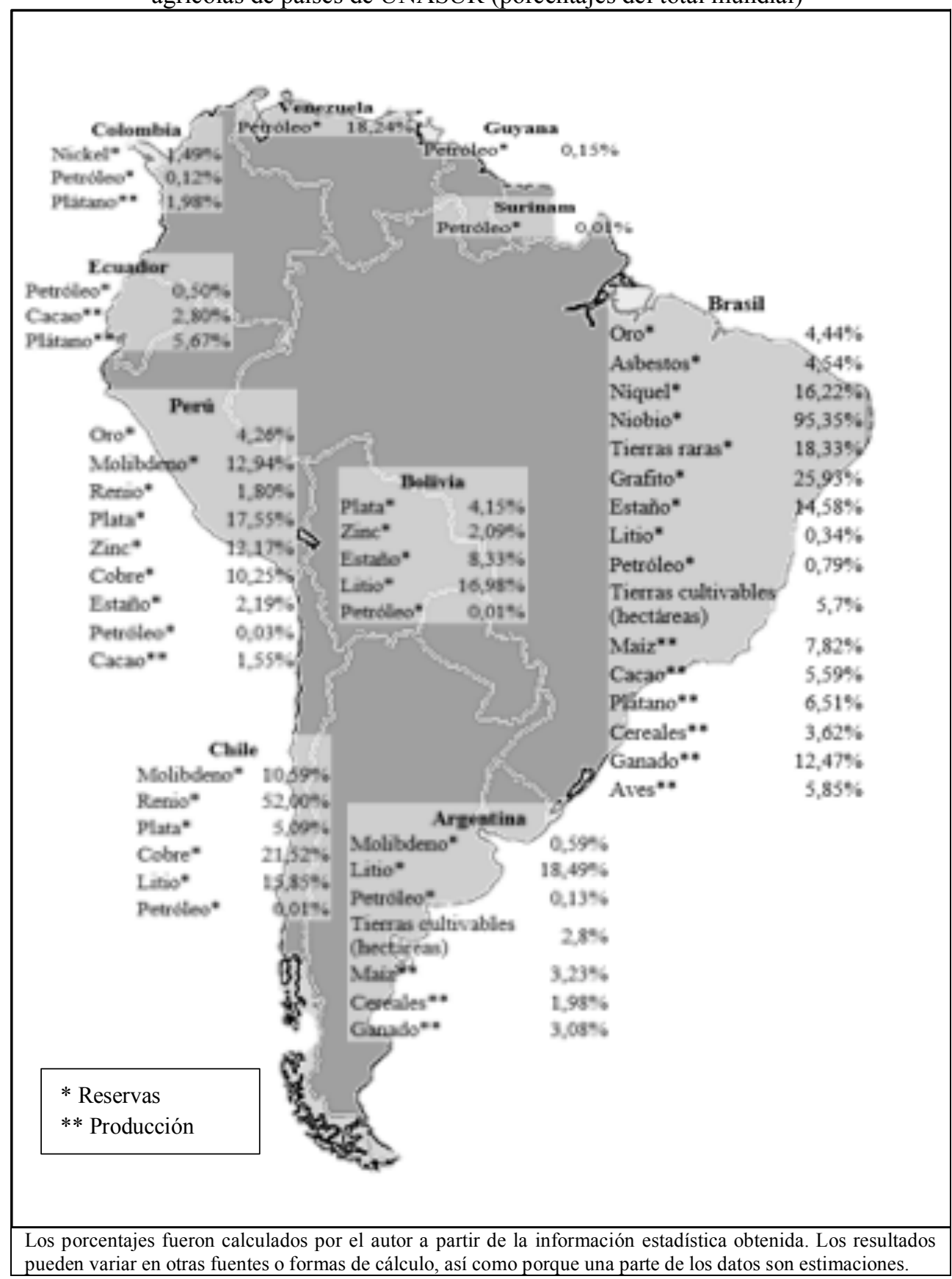

Fuentes: USGS, 2018; CIA, 2019; Banco Mundial, 2019b; Actualitix, 2018. Elaboración propia. 
Como epílogo de lo que fue el esperanzador ciclo de gobiernos multilateralistas de los primeros tres lustros del siglo XXI, se podría decir que los gobiernos regionales multilateralistas emprendieron una respetable tarea de redistribución de la riqueza, construcción de infraestructura, inversión social, así como de empoderamiento regional y desafío a Occidente durante el boom de precios. Pero estas acciones no libraron a Latinoamérica de sus históricas vulnerabilidades, que no tardaron en volver. El boom de precios fue una oportunidad histórica aprovechada a medias.

\section{Conclusiones}

Aun con los resultados no del todo satisfactorios, respecto a los que bien pudieron alcanzarse, el periodo de empoderamiento regional latinoamericano de los primeros quince años del siglo XXI dejó interesantes resultados y lecciones:

- La posesión de recursos naturales es una herramienta geopolítica de inestimable valor y alcance geoestratégico, la cual puede ser utilizada con el legítimo objetivo de tratar de equilibrar la balanza geopolítica centro-periferia.

- Las reservas de recursos naturales son poder, puesto que el intenso consumo material de las economías centrales no puede prescindir de ellos. Si bien la mayor parte de los estudiosos de la dependencia latinoamericana se han concentrado en la dependencia de la región hacia los centros, la dependencia de los centros hacia los recursos naturales de la región es un hecho geoestratégico manifiesto y muy trascendente, que debería ser estudiado científicamente para poder ser utilizado con mayores garantías de éxito

- La extensa geografía latinoamericana, así como su demografía, entre otras estratégicas cuestiones, deben también ser utilizadas como factores de empoderamiento. El discurso neoliberal, centrado exclusivamente en las relaciones comerciales, viéndolas como medio y fin, no tiene cabida en un mundo donde la tendencia global a la regionalización vuelve necesaria la utilización de la extensión territorial, la producción, el factor demográfico y la dotación socio-espacial de recursos naturales, como herramientas de inserción en el tablero de juego para la distribución del poder internacional. La región latinoamericana es relativamente abundante en los factores mencionados. Sin embargo, su escasa integración política y económica no permiten usarlos en una estrategia cohesionada?

- En definitiva, los cambios de las últimas décadas en el orden internacional fueron favorables para las periferias. El encumbramiento de las semiperiferias, el declive de la hegemonía unipolar estadounidense, el avance global de la industria que eleva la demanda de recursos naturales, fueron factores que reforzaron en un alto grado la capacidad negociadora de las periferias latinoamericanas y disminuyeron sus niveles de dependencia. No existen certezas de que una situación internacional tan favorable vuelva a

9 Al respecto, se recomienda consultar la obra de Rocha y Morales Ruvalcaba (2011). Los autores proponen medir el poder de una nación en el mundo aplicando lo que denominan el "índice de poder mundial". Entre los principales factores de poder que mide el índice, están la extensión geografía, la demografía y el producto. 
presentarse. Sin embargo, Latinoamérica debe estar preparada y no debe abandonar, sino consolidar, las instituciones de gobernanza regional que construyó para responder como bloque.

Estas "lecciones" deben ser estudiadas por los académicos y políticos latinoamericanos que quieran proponer la autonomía de la región, para proponer una estrategia geopolítica común a partir de la cual conformar un sólido frente colectivo regional, que aproveche sus fortalezas frente a los centros, que, aunque pocas, existen. Pero, deben atender también a las persistentes debilidades de la región: fundamentalmente, la endémica dependencia financiera de las periferias hacia los centros no permite que sus recursos generen el poder negociador suficiente para acortar las asimetrías relativas de poder. Para desarrollar este tipo de políticas es, por tanto, necesario buscar alianzas con las economías emergentes, que son las mayores tenedoras de reservas en este periodo histórico, y tienen a su vez necesidades crecientes de recursos, que las llevan a competir con los centros en los mercados internacionales. Por eso, durante este periodo, la estrategia latinoamericana de acercamiento a las economías emergentes fue adecuada para lograr la autonomía, pero al estar fundamentada en el mismo tipo de inserción histórica primario-exportadora, resultó en un empoderamiento demasiado frágil para sostenerse en el largo plazo.

A su vez, el empoderamiento derivado del boom de precios de las materias primas resultó adolecer de las clásicas vulnerabilidades de las periferias. La subida de precios encumbró el poder negociador internacional de Latinoamérica; luego, de igual forma, la bajada de precios lo derrumbó. La demanda de las economías emergentes elevó los precios, pero no disminuyó las vulnerabilidades.

Ser un territorio de vocación predominantemente primario exportadora sigue significando ser una región situada en los puestos más vulnerables de la escala de poder mundial, incluso en periodos de elevados precios. Esto se observó de manera más evidente en el caso de las economías eminentemente petroleras. Las periferias petroleras tienen la posesión del recurso, pero las economías desarrolladas siguen teniendo la ventaja tecnológica. Así, por ejemplo, el fracking, no solo constituyó un avance tecnológico económicamente rentable, sino además una herramienta geopolítica de gran alcance, que demostró que a la larga la tecnología vence en el juego económico y de poder mundial. De esto se deriva una quinta lección que deja el periodo del boom de precios:

- Los recursos naturales son fuente de poder geopolítico, pero este poder es tan inestable como los son los precios de éstos. Por tanto, ninguna estrategia geopolítica regional resultará efectiva en el largo plazo si no se acompaña por un plan regional de desarrollo científico-tecnológico y aumento del valor agregado de las exportaciones. Todo ello con el objetivo de disminuir las vulnerabilidades regionales ante las fluctuaciones de precios de las materias primas.

Además, ese atraso tecnológico de Latinoamérica y su consecuente continuidad como exportador neto de productos primarios hacen que la desposesión (Harvey, 2004) continúe aun durante periodos como el boom de precios y con sus nuevos socios, las economías emergentes. El histórico intercambio desigual sigue siendo la constante histórica. 
El periodo del boom de precios pudo ser de alguna manera un periodo de involución capitalista (Frank, 1976), por la desconexión momentánea y parcial de la región latinoamericana con el ciclo sistémico de acumulación principal, el ciclo estadounidense. En aquel periodo, Latinoamérica ensayó formas alternativas de organización económica; pero su atraso tecnológico y la débil integración económica regional, no permitieron que se convierta en un periodo de involución capitalista activa., pues continuó su subordinado rol de abastecedor de recursos para el histórico sistema de acumulación capitalista, y no emprendió un proceso de acumulación propio. Por eso, al terminarse el boom de precios de las materias primas, los discursos alternativos retrocedieron, y Latinoamérica se encuentra actualmente en una posible nueva reconexión al sistema principal.

En síntesis, durante el boom de precios hubo un esperanzador intento regional de construir una estrategia de poder frente a los centros, que lastimosamente fue truncado por la caída de precios de las materias primas que debilitó a los gobiernos con tendencias integracionistas y multilaterales.

Para desarrollar una política de inserción multilateral, Latinoamérica necesita, de manera acuciante, construir una estrategia de inserción activa regional de largo plazo, que incluya el aprovechamiento de las complementariedades y ventajas comerciales para sus productos manufacturados, lo cual generaría el paulatino desarro1lo tecnológico que reduzca sus vulnerabilidades (Espinoza \& Casanova, 2015). Al mismo tiempo, su estrategia debe incluir una óptima utilización para sus propios intereses de su poder negociador con las semiperiferias, las cuales, hasta ahora, si bien han aminorado la dependencia de la región latinoamericana hacia los centros, solo demuestran interés en sus materias primas y no en sus productos con valor agregado y contenido tecnológico. De esta forma se disminuiría la tradicional dependencia latinoamericana a los mercados, la tecnología y las finanzas de los centros e incluso de las economías emergentes. Construir esta estrategia queda pendiente para futuros trabajos.

\section{Bibliografía}

Actualitix (2018) "World atlas - Statistics by country". Actualitix [Puesto en linea en 2016. URL: < https://es.actualitix.com/>. Consultado el 25 de abril de 2019].

Aljazeera (2010) “The axis of Brazil". Aljazeera [Puesto en línea el 22 de mayo de 2010. URL: <www.aljazeera.com/focus/2010/05/201051863755456601.html>. Consultado el 20 de diciembre de 2016].

Amin, Samir (2001) Escritos para la transición. La Paz: Vicepresidencia del Estado Plurinacional de Bolivia.

Arrighi, Giovanni (2007) Adam Smith en Pekin, Orígenes y fundamentos del siglo XXI. Madrid: Ediciones Akal.

Ash, Timothy Garton (2007) "Davos 07: how power has shifted". The Guardian [Puesto en línea el 24 de enero de 2007. URL: <https://www.theguardian.com/commentisfree/2007/jan/24/davos07howpowerhasshifted >. Consultado el 10 de febrero de 2017].

Banco Mundial (2019a) "World Bank Commodity Price Data (The Pink Sheet)". Banco Mundial [Puesto en línea en abril de 2019. URL: <http://www.worldbank.org/en/research/commodity-markets $>$. Consultado el 19 de abril de 2019]. 
Banco Mundial (2019b) "Datos". Banco Mundial [Puesto en línea en 2019. URL: $<$ https://datos.bancomundial.org/indicador $>$. Consultado el 22 de abril de 2019].

BBC (2018) "Los presidentes y expresidentes latinoamericanos salpicados por el escándalo Odebrecht, «la mayor red de sobornos extranjeros de la historia»". $B B C$ [Puesto en línea el 22 de marzo de 2018. URL: $<$ https://www.bbc.com/mundo/noticias-america-latina$38905411>$. Consultado el 29 de abril de 2019].

BID (2009) "Capital Social y poder de Voto". Banco Internacional de Desarrollo [Puesto en línea en febrero de 2009. URL: <http://www.iadb.org/es/acerca-del-bid/capital-social-ypoder-de-voto,3166.html>. Consultado el 6 de mayo de 2017].

Bruckmann, Mónica (2012) Recursos Naturales y la Geopolítica de la Integración Sudamericana. Quito: Instituto de Altos Estudios Nacionales.

Brzezinski, Zbigniew (septiembre/octubre de 2009) “An agenda for Nato". Foreign Affairs [Puesto en línea en septiembre de 2009. URL: <https://www.foreignaffairs.com/articles/europe/2009-09-01/agenda-nato $>$. Consultado el 20 de mayo de 2017].

Caetano, Gerardo (2019) "Los nuevos rumbos del MERCOSUR el cambio de modelo y las consecuencias de la crisis Brasileña”. Foro internacional, vol. 59, núm. 1, 47-88.

CEPAL (2012a) La República Popular China y América Latina y el Caribe: Diálogo y cooperación ante los nuevos desafios de la economía global. Santiago: Naciones Unidas.

CEPAL (2012b) Panorama de Inserción Internacional de América Latina y el Caribe. Santiago de Chile: Naciones Unidas.

CEPAL (2013) Recursos naturales en UNASUR: situación y tendencias para una agenda de desarrollo regional. Santiago: Naciones Unidas.

CIA (2019) "The World Factbook 2018". CIA [Puesto en linea en 2019. URL: $<$ https://www.cia.gov/library/publications/download/download-2018/index.html $>$. Consultado el 25 de abril de 2019].

Clarín (2005) "Kirchner decidió cancelar ya toda la deuda con el FMI: 9810 millones de dólares". Clarín [Puesto en línea el 16 de diciembre de 2005. URL: <http://edant.clarin.com/diario/2005/12/16/elpais/p-00315.htm>. Consultado el 14 de diciembre de 2014].

Clarín (2018) "La Argentina vuelve al FMI: reacciones tras el anuncio de Mauricio Macri". Clarín [Puesto en línea el 8 de mayo de 2018. URL: <https://www.clarin.com/politica/negociacion-argentina-fmi-reacciones-despues-anuncio-mauricio-macri_0_Sy2tfI1RM.html>. Consultado el 26 de abril de 2019].

CNN (2016a) "Estados Unidos tiene más reservas de crudo que Arabia Saudita y Rusia". CNN [Puesto en línea el 7 de julio de 2016. URL: <http://cnnespanol.cnn.com/2016/07/07/estados-unidos-tiene-mas-reservas-de-crudo-que-arabia-saudita-y-rusia/>. Consultado el 16 de diciembre de 2016].

CNN (2016b) "7 preguntas y respuestas para entender la operación Lava Jato". CNN [Puesto en línea el 26 de septiembre de 2016. URL: < https://cnnespanol.cnn.com/2016/09/26/7preguntas-y-respuestas-para-entender-la-operacion-lava-jato/0>. Consultado el 28 de abril de 2019].

Deutsche Welle (2012) "Ecuador espera obtener respaldo de la OEA". Deutsche Welle [Puesto en línea el 23 de agosto de 2012. URL: <http://www.dw.com/es/ecuador-esperaobtener-respaldo-de-la-oea/a-16190054>. Consultado el 22 de Junio de 2017].

Ecuador Inmediato (2007) "Ecuador se suma a Venezuela y paga su deuda con el FMI". Ecuador Inmediato [Puesto en línea el 16 de abril de 2016. URL: <www.ecuadorinmediato.com/index.php? module $=$ Noticias $\&$ func $=$ news_user_view\&id $=52425 \& u m t=$ ecuador_se_suma_a_venezuela_y_paga_deuda_a_fmi $>$. Consultado el 20 de diciembre de $2014]$. 
El Nuevo Herald (2012) "Malvinas: ALBA estudiará aplicar sanciones contra Londres y retirada de TIAR". El Nuevo Herald [Puesto en línea el 5 de febrero de 2012. URL: $<$ www.elnuevoherald.com/2012/02/05/1118651/malvinas-alba-estudiara-aplicar.htmlstorylink=cpy ElNuevoHerald.com.>. Consultado el 1 de octubre 2014].

El País (2005) "La petrolera china CNOOC quiere adquirir la firma Unocal de EE UU". El País [Puesto en línea el 8 de enero de 2005. URL: <http://elpais.com/diario/2005/01/08/economia/1105138808_850215.html $>$. Consultado el 27 de junio de 2017].

El Telégrafo (2018) “Unasur, el edificio inteligente que servirá para la educación”. El Telégrafo [Puesto en línea el 6 de julio de 2018. URL: $<$ https://www.eltelegrafo.com.ec/noticias/politica/3/sede-unasur-universidad-indigena-moreno-quito $>$. Consultado el 26 de abril de 2019].

El Universo (2007) "Chiriboga: Revisión de contratos petroleros es política de Estado". El Universo [Puesto en línea el 7 de septiembre de 2007. URL: <www.eluniverso.com/2007/09/07/0001/9/A39B8FB2DA124DE19EDA1A04A57FC45F.html>.

Consultado el 20 de diciembre de 2014].

El Universo (2009) "Ecuador retoma la base de Manta". El Universo [Puesto en línea el 18 de septiembre de 2009. URL: <www.eluniverso.com/2009/09/18/1/1355/ecuador-retoma-base-manta.html $>$. Consultado el 20 de diciembre de 2014].

Erten, Bilge \& Ocampo, José (2013) "Super cycles of commodity prices since the mid-nineteenth century". World Development, vol. 44, 14-30.

Espinoza, Edwin \& Casanova, Alfonso (2015) "Análisis de las ventajas comerciales para las manufacturas ecuatorianas en la región andina, 2002-2014". Revista Científica ECOCIENCIA, vol. 2, núm. 6.

Falconí, Fander (2013) En el Sur de las Decisiones. Quito: El Conejo.

FMI (2019) "Ecuador y el FMI alcanzan un acuerdo a nivel del personal técnico sobre un apoyo de US\$4.2 mil Millones". FMI [Puesto en línea el 21 de febrero de 2019. URL: $<$ https://www.imf.org/es/News/Articles/2019/02/21/pr1952-ecuador-and-imf-reachstaff-level-agreement-on-extended-fund-facilityl $>$. Consultado el 1 de mayo de 2019].

Frank, André Gunder (1976) Capitalismo y Subdesarrollo en América Latina. México: Siglo XXI editores.

Gulévich, Vladislav (2013) “América Latina entre China y los EE UU”. Strategic Culture Fund [Puesto en línea el 18 de agosto de 2013. URL: $<$ http://www.fondsk.ru/news/2013/08/18/latinskaja-amerika-mezhdu-kitaem-i-usa22233.html $>$. Consultado el 28 de junio de 2017].

Harvey, David (2004) El nuevo imperialismo. Madrid: Akal.

Hispan TV (2019) “Ecuador entrega a Assange a la Policía británica 7 años después”. Hispan $T V$ [Puesto en línea el 11 de abril de 2019. URL: <https://www.hispantv.com/noticias/ecuador/425750/moreno-assange-extraditado-pena-muerte $>$. Consultado el 28 de abril de 2019].

Hoyos, Carola (2007) "The new seven sisters: oil and gas giants that dwarf the west's top producers". Financial Times [Puesto en línea el 12 de marzo de 2007. URL: $<$ http://www.ft.com/cms/s/0/7b407c5e-d03e-11db-94cb-

000b5df10621.html?ft_site=falcon\&desktop=trueaxzz4QxXvIuu1>. Consultado el $15 \mathrm{de}$ enero de 2017].

Jalife, Alfredo (2007) Hacia la Desglobalización. México: Jorale Editores.

La Nación (2011) “Temen que la Argentina recupere las Malvinas con el respaldo de China”. La Nación [Puesto en línea el 27 de septiembre de 2011. URL: 
$<\mathrm{http}$ ://www.lanacion.com.ar/1409745-militares-britanicos-retirados-insistieron-en-defender-las-islas-malvinas $>$. Consultado el 22 de junio de 2017].

Machado, Decio \& Zibechi, Raúl (2016) Cambiar el mundo desde arriba: los límites del progresismo. CEDLA Centro de Estudios para el Desarrollo Laboral Agrario.

MERCOSUR (2017) "Suspensión de Venezuela en el MERCOSUR”. MERCOSUR [Puesto en línea el 5 de agosto de 2017. URL: <https://www.mercosur.int/suspension-de-venezuela-en-el-mercosur/>. Consultado el 26 de abril de 2019].

Merino, Gabriel (2016) "Tensiones mundiales, multipolaridad relativa y bloques de poder en una nueva fase de la crisis del orden mundial. Perspectivas para América Latina". Geopolítica(s). Revista de estudios sobre espacio y poder, vol. 7, núm. 2, 201-225.

Moniz, Luis (2016) Entrevista con Sergio Lirio [Puesto en línea el 19 de mayo de 2016. URL: $<$ https://www.amersur.org/politica-internacional/brasil-el-golpe-y-la-geopolitica-monizbandeira/>. Consultado el 28 de abril de 2019].

Morales Ruvalcaba, Daniel; Rocha Valencia, Alberto \& Vargas García, Elizabeth (2014) "Las potencias regionales como protagonistas del sistema político internacional: cooperación y diálogo en el Foro BRICS”. Geopolitica(s). Revista de estudios sobre espacio y poder, vol. 4, núm. 2, 237-261.

Narodowski, Patricio \& Merino, Gabriel (2015) "La agudización de las tensiones globales. Análisis de la crisis del orden unipolar y los conflictos geoestratégicos desde una perspectiva centro-periferia". Estudios Socioterritoriales, núm. 18, 81-99.

Observatorio de la Política Fiscal (2007) "Patiño anuncia el pago total de la deuda al FMI". Observatorio de la Política Fiscal [Puesto en línea el 10 de enero de 2007. URL: $<$ www.observatoriofiscal.org/documentos/noticias-de-prensa/el-expreso/287.html $>$. Consultado el 20 de diciembre de 2014].

OEA (2004) “Organización de Estados Americanos, Consejo Permanente: Otorgamiento a la República Popular China de la condición de Observador Permanente ante la Organización". Organización de Estados Americanos [Puesto en línea el 26 de mayo de 2004. URL: <http://www.oas.org/consejo/sp/resoluciones/res867.asp>. Consultado el 22 de julio de 2014].

OLADE (2012) "Panorama general de los hidrocarburos no convencionales". Organización Latinoamericana de Energía [Puesto en línea en julio de 2012. URL: <www.olade.org/sites/default/files/publicaciones/Documento\%20Tecnico\%20nueva\%20portada.pdf $>$. Consultado el 5 de mayo de 2017].

Rocha Valencia, Alberto \& Morales Ruvalcaba, Daniel Efrén (2011) Potencias medias y potencias regionales en el sistema político internacional de Guerra Fría y Posguerra Fría. Propuesta de dos modelos teóricos. Guadalajara: Universidad de Guadalajara.

Rodríguez, Isabel \& Leiva Van de Maele, Diego. (2013) “El soft power en la política exterior de China: consecuencias para América Latina”. Polis, Revista Latinoamericana. vol. 12, núm. 35, 497-517.

Sputnik (2007) "La Guerra Fría fue un paraíso en comparación con las amenazas actuales, opina el ministro de defensa ruso". Sputnik New [Puesto en línea el 16 de enero de 2007. URL: <https://mundo.sputniknews.com/noticias/2007011659160088/>. Consultado el 16 de febrero de 2017].

Sputnik (2019) “Ecuador será sede en 2020 de maniobras militares Unitas”. Sputnik [Puesto en línea el 26 de abril de 2019. URL: <https://mundo.sputniknews.com/defensa/201904261086924121-ecuador-sede-de-maniobras-militares-unitas/>. Consultado el 29 de abril de 2019].

Svampa, Maristella (2013) “«Consenso de los Commodities» y lenguajes de valoración en América Latina”. Nueva Sociedad, núm. 244, 30-46. 
Últimas Noticias (2011) "Puertos de región no abastecerán buques con bandera de Malvinas". Últimas Noticias [Puesto en línea el 21 de diciembre de 2011. URL: <www.ultimasnoticias.com.uy/Edicion-UN/articulos/prints-2011 dic21/act04.html $>$. Consultado el 21 de diciembre de 2014].

USDA (2012) United States Department of Agriculture, Economic Research Service, China [Puesto en linea en 2012. URL: <www.ers.usda.gov/topics/international-marketstrade/countries-regions/china.aspx $>$. Consultado el 2 de marzo de 2014].

USGS (2012) "An Estimate of Undiscovered Conventional Oil and Gas Resources of the World, 2012". USGS [Puesto en linea el 18 de abril de 2012. URL: $<$ http://pubs.usgs.gov/fs/2012/3042/>. Consultado el 19 de enero de 2017].

USGS (2018) “Mineral commodity summaries, 2018". USGS [Puesto en linea en 2019. URL: $<$ https://minerals.usgs.gov/minerals/pubs/mcs/2018/mcs2018.pdf $>$. Consultado el 25 de abril de 2019].

Van Klaveren, Alberto (2018) "El eterno retorno del regionalismo latinoamericano". Nueva Sociedad, núm. 275, 62-72.

Wallerstein, Immanuel (2005) “Globalización o era de transición?”. Eseconomía, Nueva Época, núm. 1, 5-17.

Webb-Vidal, Andy (2006a) "Venezuela «will not cut off oil» to US". Financial Times [Puesto en línea el 31 de junio de 2006. URL: <https:/www.ft.com/content/1a1954d620bd-11db-8b3e-0000779e2340>. Consultado el 22 de marzo de 2017].

Webb-Vidal, Andy (2006b) "Chávez seeks to link Putin with anti-US Alliance". Financial Times [Puesto en línea el 25 de julio de 2006. URL: <https://www.ft.com/content/1cb0bbce-1c0a-11db-a555-0000779e2340>. Consultado el 28 de marzo de 2017]. 